\title{
Subvenção econômica da FINEP 2006-2009: política e território no sistema de inovação brasileiro
}

FINEP Economic Subsidy 2006-2009: politics and territory in the Brazilian innovation system

Les subventions économiques de la FINEP 2006-2009: politique et territoire dans le système d'innovation brésilien

Subvención económica de la FINEP 2006-2009: política y territorio en el sistema brasileño de innovación

\section{Pablo Ibanez}

\section{(2) OpenEdition} Journals

Edição electrónica

URL: https://journals.openedition.org/espacoeconomia/21352

DOI: 10.4000/espacoeconomia.21352

ISSN: 2317-7837

Editora

Núcleo de Pesquisa Espaço \& Economia

Refêrencia eletrónica

Pablo Ibanez, «Subvenção econômica da FINEP 2006-2009: política e território no sistema de inovação brasileiro», Espaço e Economia [Online], 22 | 2021, posto online no dia 14 janeiro 2022, consultado o 11 agosto 2022. URL: http://journals.openedition.org/espacoeconomia/21352 ; DOI: https://doi.org/10.4000/espacoeconomia.21352

Este documento foi criado de forma automática no dia 11 agosto 2022. 


\title{
Subvenção econômica da FINEP 2006-2009: política e território no sistema de inovação brasileiro
}

\author{
FINEP Economic Subsidy 2006-2009: politics and territory in the Brazilian \\ innovation system \\ Les subventions économiques de la FINEP 2006-2009: politique et territoire dans \\ le système d'innovation brésilien \\ Subvención económica de la FINEP 2006-2009: política y territorio en el sistema \\ brasileño de innovación
}

\section{Pablo Ibanez}

\section{Introdução}

Apesar de os financiamentos públicos para inovação tecnológica nas empresas serem conhecidos e utilizados por vários países, o Brasil apresenta ainda uma história recente, porém não menos importante. As experiências de mecanismos de financiamento público para inovação no país têm crescido nos últimos anos, o que demonstra uma necessidade, cada vez mais urgente, de análises de efetividade e qualidade dos desembolsos governamentais. Devido o grau de incerteza que o retorno financeiro para investimentos em inovações apresenta, os financiamentos para essas atividades são, em sua maioria, escassos na esfera privada, e na esfera pública, apesar do relativo consenso da necessidade de criar mais e melhores financiamentos, foi só na segunda metade da década de 2000 que tivemos a consolidação de linhas mais sólidas tanto de financiamentos reembolsáveis, como de não-reembolsáveis. É nesse sentido que se pretende avaliar nesse texto ${ }^{1}$ a principal linha de financiamento não-reembolsável do país, a Subvenção Econômica à Inovação da Financiadora de Estudos e Projetos (FINEP), em relação aos seus aspectos qualitativos e quantitativos. 
Esse modelo de financiamento teve sua primeira versão no ano de 2006 e desde então sofreu algumas transformações. É importante ressaltar que quando tratamos de subvenção econômica, não nos referimos apenas a sua modalidade de financiamento direto às empresas, mas também as linhas do PAPPE Subvenção, gerida pelas Fundações de Amparo à Pesquisa (FAPs) em alguns estados brasileiros. Porém, aqui nos resguardaremos unicamente a análise dos editais da Subvenção Econômica à Inovação, que até o momento contabilizam quatro editais com participação de milhares de empresas, recursos da ordem de $\mathrm{R} \$ 1.569$ milhões e 825 contratos até o ano de 2009.

A análise dessa linha de financiamento tem um apelo territorial muito forte, afinal seus desembolsos só confirmam a grande concentração espacial de atividades ligadas a CT\&I. o Sudeste é o grande 'ganhador' dos projetos e suas empresas as que mais se mostram aptas a conseguir o financiamento. E isso passando pelo detalhe de todos os editais até hoje terem resguardado uma percentagem de $30 \%$ do total disponibilizado para as regiões Nordeste, Norte e Centro-Oeste, ou seja, as tentativas de desconcentração do desembolso não se efetivam, o que merece atenção. Por outro lado, sua dimensão geopolítica não pode ser desprezada, sobretudo, por definir áreas estratégicas que visam a diminuição da dependência na produção de certas tecnologias, como de defesa nacional, saúde e biotecnologia.

Por se tratar de uma linha completamente inédita, já que até o final do ano de 2004, o financiamento não-reembolsável para as empresas era proibido por lei, se pretende, em primeiro lugar, realizar a trajetória legal e institucional que tornou possível esse mecanismo, assim como suas dificuldades de efetivação e seus laços com a Política Industrial Tecnológica e de Comercio Exterior (PITCE), o Plano de Ação de Ciência, Tecnologia e Inovação 2007-2011 (PACT\&I) e a Política de Desenvolvimento Produtivo (PDP). No que se refere a questão legal, a subvenção parece estar de acordo com o que Bastos (2006:425) alertava tendo em vista as restrições do comercio internacional aos apoios diretos às atividades produtivas, afinal ações como a subvenção são praticadas em países desenvolvidos na promoção da competitividade, "ainda que através de ações dirigidas às pequenas e médias empresas, à redução das disparidades regionais, às adaptações decorrentes das mudanças ambientais e ao apoio à pesquisa e desenvolvimento", elementos estes presente na subvenção praticada pelo Brasil. Já no que tange a questão legal, além dos aspectos constitutivos que deram escopo ao financiamento, abordar-se-á a necessidade de melhoria da Lei 8.666, a lei que trata das compras públicas no Brasil. Pela subvenção ter delimitado áreas consideradas estratégicas para o desembolso, a efetividade da política teria melhores resultados se, atrelado ao financiamento, tivéssemos um poder de compra do Estado atuando para efetivar as inovações dos projetos financiados pela própria subvenção e por outras políticas governamentais. Por fim, será realizada uma apreciação do processo de aquisição de duas empresas contempladas com contratados da subvenção e que posteriormente foram adquiridas por uma empresa multinacional, que também se configura como uma questão crucial, já que a subvenção pressupõe o desenvolvimento de inovações em empresas brasileiras.

Em um segundo momento, será realizada uma análise mais quantitativa da política, utilizando o banco de dados organizado pelo Instituto de Pesquisa Econômica Aplicada (IPEA) ${ }^{2}$. Uma série de análises dos números da Subvenção, sua trajetória, algumas mudanças nos editais que trouxeram consequentes alterações no padrão das empresas contratadas, assim como a relação das empresas que participaram do financiamento e a 
relação dessas com outros mecanismos de financiamento, tanto da FINEP quanto de outras instituições públicas, como o BNDES e o CNPq. Também será dada ênfase na análise do perfil das empresas com base em três recortes: por Unidades da Federação (UF); por porte; e pela comparação entre as empresas da RAIS, dos Fundos Setoriais e da própria subvenção econômica. Dessa forma, se pretende dar um panorama mais amplo do financiamento, apontando suas beneficies e gargalos, assim como seus desafios para a consolidação deste tipo de financiamento à inovação tecnológica no país.

\section{Legislações e instituições}

O ano de 2004 pode ser considerado um marco para as políticas de inovação no Brasil. Tendo uma trajetória legal voltada aos financiamentos para ciência e tecnologia já desenvolvida e bem estruturada, o Brasil passou a contar, a partir desse ano, com a possibilidade de financiamento público direto às empresas com projetos ligados à inovação.

As importantes mudanças legais que permitiram esse financiamento foram acompanhadas de transformações institucionais em órgãos que tiveram, originalmente, sua criação voltada ao financiamento de projetos ligados à ciência e tecnologia em centros de pesquisa públicos, universidades e outras instituições sem fins lucrativos. E nesse sentido que um resgate histórico institucional se torna fundamental.

Por ser a instituição que opera a Subvenção Econômica, as atenções aqui estarão voltadas as especificidades da FINEP, aos fundos operados por ela e às legislações diretamente relacionadas às possibilidades tanto de existência dos fundos, quanto de operação de financiamentos à esfera privada por parte da financiadora.

Inicialmente a FINEP foi criada em 1965 como um fundo, o Fundo de Financiamento de Estudos e Projetos, ligado ao BNDE, e seus objetivos estavam mais voltados a viabilização de estudos de programas e propostas de investimentos. Poucos anos depois, em 1967, esse fundo veio a se tornar uma empresa pública, que manteve a sigla, mas com objetivo mais amplo: avaliar a viabilidade de projetos do Ministério do Planejamento, (PIRRÓ E LONGO e DERENUSSON, 2009:517). Desde então a FINEP passou a ter papel central nas políticas de financiamento da C\&T no país.

No final da década de 1960, como relata Ferrari (2002:151) com base nos Relatórios Anuais da FINEP, já havia uma percepção da necessidade de expansão da base produtiva sincronizada com uma revolução cientifica e tecnológica em curso em várias partes do mundo. Neste sentido, no ano de 1969 é criado, através do Decreto Lei n19, o Fundo Nacional de Desenvolvimento Científico e Tecnológico (FNDCT). Sua finalidade era exatamente dar apoio aos programas e projetos de C\&T para a implantação do Plano Básico de Desenvolvimento Científico e Tecnológico (PBDCT), que teria sua primeira versão promulgada em 1973. Quando do seu lançamento, o fundo previa um conselho diretor, constituído por representantes de diversos ministérios, além de instituições como o BNDES e CNPq, e previa também a criação de uma Secretaria Executiva, que só veio a ser efetivada em 1971 pelo Decerto $n^{\circ}$ 68.748, que delegou à FINEP essa função.

Com o desenvolvimento, sobretudo, de três programas, o de Apoio à Consultoria Nacional - ACN, o Apoio ao Usuário dos Serviços de Consultoria - AUSC, Programa de Apoio ao Desenvolvimento Tecnológico da Empresa Nacional - ADTEN, a FINEP que apoiava apenas empresas de consultoria, passou a operar "em todo o espectro do desenvolvimento científico e tecnológico" (PIRRÓ E LONGO e DERENUSSON, 2009:518). 
Segundo os mesmos autores, a simbiose entre o FNDCT e a FINEP foi, durante esses quarenta anos que se seguiram, "o mais poderoso instrumento de desenvolvimento científico e tecnológico” do país.

Durante a década de 1970, com recursos oriundos do Banco Interamericano de Desenvolvimento, o FNDCT teve fundamental importância para a consolidação de importantes instituições vinculadas ao sistema nacional de C\&T brasileiro, a exemplo da Comissão Nacional de Energia Nuclear (CNEN), uma das sete primeiras beneficiarias do fundo. Esse quadro seria mantido ainda na década de 1980, que apesar da diminuição dos desembolsos, não foi tão ruim quanto a década que estava por vir, os anos 1990 (idem).

Até a década de 1990, um sistema voltado ao desenvolvimento científico e tecnológico havia sido criado no Brasil, com o fortalecimento de ICTs, mas o mesmo não podia ser afirmado em relação à inovação tecnológica nas empresas, salvo empresas públicas com setores de desenvolvimento tecnológico estruturado. Um dos poucos casos voltados às empresas privadas foram as isenções fiscais previstas no Decreto-Lei 2.433/86. Porém, se observados o FNDCT e a própria FINEP, não encontraremos nenhum aporte voltado para o setor produtivo privado.

Já no decorrer dos anos 1990, as iniciativas estruturais tomadas em direção a um sistema nacional de inovação mais efetivo não surtiram o mesmo efeito daquelas que viriam a ocorrer durante os anos 2000. É nesse sentido que um breve resgate se torna necessário, para que possa fazer sentido o papel que a FINEP passou a exercer nos últimos anos.

Quando analisamos a década de 1990, em que foram implementadas políticas econômicas mais ortodoxas, duas questões principais despontam como explicação para o fraco desempenho brasileiro em relação à inovação tecnológica: a ausência de políticas industriais, e os cortes de gasto em áreas relacionadas à educação e P\&D. Obviamente que os cortes realizados foram, em grande parte, conseqüência da hiperinflação e da incapacidade de ajustes das contas públicas herdadas da década anterior. De qualquer forma, em termos de políticas diretamente voltadas ao setor produtivo, o período teve fraco desempenho.

Villaschi (2005) realizou um esforço de captar quais foram as principais razões que levaram ao relativo 'abandono' das políticas de inovação. Inicialmente, o autor nos remonta à década de 1980 em que “o papel desempenhado pelas empresas estatais e pelos laboratórios de pesquisa públicos em áreas que estavam no cerne do PTE (paradigma tecnológico-econômico) da TIC (tecnologias da informação e das comunicações) e a maneira como a tripla aliança entre empresas locais, estrangeiras e estatais vinha funcionando poderia ser uma indicação positiva de possibilidades" para o Sistema Nacional de Inovação Brasileiro. Porém, questões como o forte protecionismo, as altíssimas taxas inflacionárias e o déficit público, reduziam sua eficiência e quando entramos na década de 90 tivemos mudanças radicais do ponto de vista econômico.

A liberalização econômica não trouxe investimentos externos produtivos em áreas em que novos conhecimentos são fundamentais. O setor farmacêutico pode ser um bom exemplo disso, já que os investimentos em PD\&I, até hoje, são realizados majoritariamente nos países de origem das empresas multinacionais, restando aqui processos simples como a embalagem, fato contribuiu e contribui com o crescente déficit na balança comercial do setor ${ }^{3}$. Outro ponto, foi o corte de gastos em áreas essenciais, como educação e P\&D, gerados pelo déficit público oriundo das décadas 
anteriores. E por fim, a própria questão das empresas, que mantiveram estratégias defensivas quanto à inovação, mesmo aquelas localizadas em regiões mais dinâmicas do Brasil (VILLASCHI, 2005).

Outros fatores que incidiram direta e indiretamente sobre o desenvolvimento da inovação tecnológica foram levantados por Coutinho (2003). As altas taxas de juros e o câmbio sobrevalorizado se mostraram fundamentais para o aumento das importações, com destaque para máquinas, fato que diretamente afetou a promoção de políticas de inovação dentro das empresas, dado que boa parte das despesas era utilizada por essas compras. Não menos importante foi também a fragilidade observada em setores de grande conteúdo tecnológico, já que muitas empresas foram compradas ou não conseguiram manterem-se competitivas em relação às empresas multinacionais.

É evidente que todos esses apontamentos, principalmente de cunho macroeconômico, tiveram relação com o fraco desempenho inovativo tanto nas políticas de governo, como no desenvolvimento de P\&D dentro das empresas. Por outro lado, não se pode perder de vista a atuação dos governos na condução de políticas para o setor produtivo. Nas palavras de Arbix e Mendonça (2005:255) no "início da década de 1990 a desarticulação da política de C\&T e da política industrial no Governo Collor não deixou espaço para políticas ativas, e a relação com o setor empresarial passou a ser regida pela introdução de instrumentos de política horizontais e pela visão de que a qualidade e a abertura de mercado resolveriam os problemas da competitividade". Ou seja, ficou evidente a fraca participação do Estado nas políticas de CT\&I.

Porém, quando analisamos as experiências bem-sucedidas de países que tiveram desenvolvimento tecnológico como parte da política de desenvolvimento, a atuação do Estado aparece como fundamental. Salerno e Kubota (2008:17) salientam que as atividades intensivas em conhecimento são de fundamental relevância política tendo em vista que "os governos, de todos os principais países do mundo, e daqueles aspirantes a tal posto, desenvolvem instrumentos de apoio ao desenvolvimento da ciência, da tecnologia e da inovação pelas empresas". Afinal, é inegável a importância da inovação tecnológica como fator aumento da capacidade tecnológica, de diminuição da dependência externa e da própria criação de melhore condições de trabalho e salários nas firmas ${ }^{4}$.

A participação do Estado, através de incentivos para a inovação, é apontada como elemento central e utilizado por vários países, principalmente os desenvolvidos. Segundo Avellar (2008), os incentivos têm majoritariamente dois enfoques: no formato, como dedução do Imposto de Renda (que varia de caso a caso) ou crédito fiscal; ou no alvo, se será direcionado para pequena, média ou grande empresa. Um dos exemplos utilizados pela autora é o Canadá, que apresenta um dos mais complexos e amplos sistemas de incentivos, que datam da década de 1960, tendo diversas mudanças em seus conteúdos, incluindo incentivos locais (criados na década de 1970) para a inovação. E ganha destaque o fato de $40 \%$ das empresas utilizarem alguma forma de incentivo, ainda muito superior ao nosso caso ${ }^{5}$.

No Brasil, mesmo sendo pequeno o número de empresas inovativas e as iniciativas de indução à inovação serem recentes, não podemos perder de vista a importância das últimas décadas em direção a consolidação de um sistema nacional de inovação mais robusto. Ainda na década de 1990, considerada como moderada nas políticas de inovação, tivemos o lançamento do Programa de Desenvolvimento Tecnológico Industrial (PDTI) em 1993. Esta iniciativa, baseada em incentivos fiscais se 
fundamentaram no Decreto-Lei 2.433/86 e depois se consolidaram, sem grandes alterações, pela Lei $n^{\circ}$ 8.661/1993. O estímulo à inovação através dessa lei, até hoje, se dá "por meio da dedução do IR e do crédito fiscal incididos no Imposto de Renda sobre Pessoa Jurídica (IRPJ), bem como no Imposto sobre Operações Financeiras (IOF)" (AVELLAR, 2008:333). Vale lembrar que esse programa ainda contou com uma ampliação no ano de 2002, em que foi criada a Lei 10.637, permitindo aos participantes o abatimento das despesas de custeio (relacionadas à pesquisa e inovação) do lucro líquido para o cálculo do IR (idem).

$\mathrm{Na}$ teia dos incentivos, que não necessariamente se dão por isenções fiscais, a lei que mais nos interessa é a Lei no 10.973 de 2004, chamada de "Lei da Inovação". Instituída como mais um mecanismo de melhoria do ambiente inovativo no Brasil, essa lei permitiu a subvenção econômica ${ }^{6}$ às empresas privadas, tipo de programa que até então não possuía aporte legal. Segundo o Artigo 19 da referida lei, as empresas nacionais passam a poder receber incentivos da União, das ICTs e das agências de fomento para desenvolvimento de produtos e processos inovadores "mediante concessão de recursos financeiros, humanos, materiais ou de infraestrutura". Além dessa novidade, fica claro no próprio artigo supracitado, que os incentivos devem atender as prioridades da política industrial e tecnológica do país, principalmente nos que tange a melhoria da eficiência do setor produtivo e capacitação tecnológica frente à competição externa. E como poderá ser observado no próximo item, as portarias ministeriais que definiram setores estratégicos para os editais da Subvenção Econômica, estão em total consonância com as políticas industriais e tecnológicas lançadas nos últimos anos.

A própria visão do Ministério da Ciência e Tecnologia ${ }^{7}$ é reveladora de uma maior integração entre os mecanismos de indução à inovação, sejam os legais, sejam os dados pela política industrial. Abaixo se apresenta um resumo do MCT sobre o marco regulatório pautado em três vertentes:

i. Constituição de ambiente propício às parcerias estratégicas entre as universidades, institutos tecnológicos e empresas. Através da estruturação de redes e projetos internacionais de pesquisa tecnológica; ações de empreendedorismo tecnológico; e criação de incubadoras e parques tecnológicos.

ii. Estímulo à participação de instituições de ciência e tecnologia no processo de inovação. Facilita a participação de ICTs em contratos de transferência de tecnologia e licenciamento de patentes, prestação de serviços em atividades do setor produtivo e participação de seus funcionários em projetos onde a inovação seja o foco.

iii. Incentivo à inovação na empresa. Estimular alocação de recurso financeiros das empresas para promoção da inovação. Concessão, por parte da União, das ICT e das agências de fomento, de recursos financeiros, humanos, materiais ou de infraestrutura, para atender às empresas nacionais envolvidas em atividades de pesquisa e desenvolvimento. Mediante contratos ou convênios específicos tais recursos serão ajustados entre as partes, considerando ainda as prioridades da política industrial e tecnológica nacional.

Paralela a essa consolidação legal, ainda tivemos a promulgação de mais uma lei de grande relevância, a "Lei do Bem". Em realidade essa lei foi resultado da revogação da Lei $\mathrm{n}^{\mathrm{0}}$ 8.661/93, promulgada como Lei $\mathrm{n}^{\mathrm{0}} 11.196$ de novembro de 2005. Entre suas características pode-se dizer que, por um lado, ela veio a fortalecer o novo marco legal instituído pela "Lei de Inovação", e por outro, consolidar os incentivos fiscais para o usufruto de pessoas jurídicas de forma automática em empresas com investimentos em pesquisa tecnológica e inovação. Além disso, segundo Salerno e Kubota (2008:35), essa lei "introduz uma ruptura conceitual de largas proporções: os incentivos fiscais para 
P\&D são de fruição automática, não exigindo, portanto, que se apresente projeto, ou que se peça autorização prévia para que possam ser usufruídos", agilizando e permitindo maior alcance dos incentivos. Os principais incentivos fiscais são dados pelos benefícios do Capítulo III, elencados abaixo:

deduções de Imposto de Renda e da Contribuição sobre o Lucro Líquido - CSLL de dispêndios efetuados em atividades de P\&D;

- a redução do Imposto sobre Produtos Industrializados - IPI na compra de máquinas e equipamentos para P\&D;

- depreciação acelerada desses bens;

- amortização acelerada de bens intangíveis;

- redução do Imposto de Renda retido na fonte incidente sobre remessa ao exterior resultante de contratos de transferência de tecnologia;

- isenção do Imposto de Renda retido na fonte nas remessas efetuadas para o exterior destinada ao registro e manutenção de marcas, patentes e cultivares.

Pode-se observar acima uma extensão maior dos incentivos à inovação dada pela lei. Por outro lado, apesar da sua importância, as isenções fiscais, ainda hoje, têm adesão muito baixa por parte das empresas no Brasil. A Tabela 1 deixa clara a afirmativa anterior, nela estão expressas as empresas cadastradas para receber os incentivos da lei. Apesar do crescente uso das isenções fiscais, quer seja no Brasil como um todo, quer seja por região, a adesão em 2008 foi de apenas 552 empresas. Quando regionalizamos esses dados a situação fica ainda mais complicada, afinal, juntas, as regiões CentroOeste, Nordeste e Norte não somam nem $10 \%$ do total de empresas cadastradas para receber os incentivos fiscais. Quantitativamente esse fato será mais bem detalhado no próximo item, já que procurou-se estabelecer o cruzamento das empresas que usufruem das isenções fiscais e da subvenção ao mesmo tempo.

Tabela 1 - Número de Empresas Cadastradas na 'Lei do Bem' por Regiões - por ano

\begin{tabular}{|c|c|c|c|}
\hline \multirow{2}{*}{ Regiões/Brasil } & \multicolumn{3}{|l|}{ Anos } \\
\hline & 2006 & 2007 & 2008 \\
\hline Sudeste & 73 & 192 & 310 \\
\hline Sul & 52 & 120 & 204 \\
\hline Centro-Oeste & 1 & 1 & 1 \\
\hline Norte & 1 & 3 & 10 \\
\hline Nordeste & 3 & 16 & 27 \\
\hline Total & 130 & 332 & 552 \\
\hline \multicolumn{4}{|c|}{ Fonte: MCT,RELATÓRIO ANUAL DA UTILIZAÇÃO DOS INCENTIVOS FISCAIS, 2008} \\
\hline
\end{tabular}

Ainda que o número de empresas participantes do exemplo anterior seja baixo, deve ficar claro que houve um aumento das possibilidades geradas pelas mudanças legais, que por sua vez gerou uma readequação de instituições, como a FINEP para o 
atendimento de novas demandas. Se olharmos a década de 1990 tanto os incentivos fiscais, quanto os próprios recursos oriundos do FNDCT, não se pode negar que os avanços subsequentes tiveram dimensões significativas. De meados dos anos 1980 até o fim da década de 1990 esse fundo contou com receitas consideradas moderadas para tal finalidade que eram em média de US\$ 50 milhões. O que também não diminui sua importância, haja vista seu papel fundamental no desenvolvimento de projetos como o do avião Tucano da Embraer, de programa de formação de recursos humanos da Embrapa e em projetos da Petrobras, (FINEP, 2004:5). De qualquer forma, em 1997, com o objetivo de aumento das alternativas para a captação de recursos, foi proposta a vinculação dos royalties do petróleo para áreas definidas como prioritárias e a criação de instrumentos normativos, bem como medidas provisórias e projetos de lei, que não vinculassem essas receitas para o fundo com as receitas oriundas de impostos. Estruturada suas fontes de recursos, o fundo tenderia a ter um crescente natural. Porém, se analisados os recursos do FNDCT, que já vinham crescendo durante a década de 1990, afinal os desembolsos em 1999 foram de aproximadamente $\mathrm{R} \$ 190$ milhões, chegam, em 2006, a cifras próximas de $\mathrm{R} \$ 790$ milhões.

Neste quadro de aumento das receitas e das próprias funções, tendo em vista a expansão dos programas de apoio a CT\&I, a FINEP passa a ser elemento crucial no sistema nacional de inovação, gerindo não só os recursos do FNDCT como também o programa Juros Zero entre outros. Ou seja, esse espectro de funções mais amplo, que passou também a credenciá-la com instituição de financiamento para empresas privadas, merece toda atenção quanto aos seus atributos internos e mecanismos de avaliação de suas atividades. Em relação às suas atribuições, segundo o Relatório de Gestão de 2009, dada a importância do programa de subvenção e da crescente demanda, a FINEP não só diminuiu o número de fases de apresentação de propostas de dois para um, com o intuito de centralizar as operações, assim como, criou uma diretoria apenas para o tratamento dos assuntos relacionados ao programa, a Diretoria de Subvenção Econômica (DSBV). É relevante também a iniciativa da Diretoria de Inovação e do Departamento de Acompanhamento da FINEP que realizou um relatório com base em entrevistas realizadas com 27 empresas contratadas pela Subvenção Econômica, exatamente no sentido de avaliação de suas atividades. 0 estudo procurou avaliar a efetividade do uso dos recursos da financiadora, assim como entraves e aspectos positivos do financiamento. Esse relatório pode ser visto como um exemplo da busca por uma melhora institucional, já que parte da preocupação com a avaliação e possíveis mudanças que podem ser sugeridas pelas partes diretamente envolvidas no processo de financiamento.

É de se esperar que essa mudança institucional da FINEP, assim como o programa de subvenção às empresas possam contribuir para o desenvolvimento do país e, sobretudo, na diminuição da dependência tecnológica externa ${ }^{8}$. Porém, ainda nesta seção, julga-se necessária a discussão do tema das compras públicas, tão importante para as políticas de inovação e ainda não integrado às mesmas de maneira efetiva. Por mais que seja inegável o avanço das políticas federais de incentivos e isenções, do ponto de vista legal o país ainda apresenta um gargalo importante de ser corrigido: a lei de normas para licitações e contrato de Administração Pública, Lei 8.666. Na referida lei, o único caso em que se verifica privilégio na contratação de serviços, por parte do poder público, de empresas que desenvolvem tecnologia no Brasil é no $2^{\circ}$ parágrafo do artigo $3^{\circ} .0$ artigo em questão, em realidade, só se aplica no caso de igualdade de condições entre empresas que participam do processo licitatório, ou seja, só assim é assegurada a 
preferência de aquisição de bens e serviços: produzidos ou prestados por empresas brasileiras de capital nacional; produzidos no País; produzidos ou prestados por empresas brasileiras; e produzidos ou prestados por empresas que invistam em pesquisa e no desenvolvimento de tecnologia no País. É importante ressaltar que essa vantagem só é assegurada quando em condições de igualdade e não em outras situações, como dando vantagem para empresas que desenvolvam projetos de inovação com financiamentos e incentivos do governo, ou mesmo, que apenas realizem inovações capazes de diminuir importações de determinado segmento econômico.

A prática do poder de compra do Estado vem sendo muito questionada e vista como um mecanismo eficiente na promoção de políticas de inovação, porém, conforme visto acima, ainda impossibilitado de ser usado no país, pela própria legislação brasileira. Elder e Georghiou (2007) realizaram um estudo sobre as potencialidades e efetividades do uso desse mecanismo. Entre algumas conclusões, os autores ressaltaram que os usos das compras públicas são mobilizadores de inovação e podem, por um lado, melhorar a qualidade das políticas públicas, e por outro, melhorar os serviços ofertados à população. Com os exemplos da União Europeia e da China, os autores citam que as compras públicas têm sido utilizadas como parte da política de inovação, nesse último país, quando as compras dizem respeito à produtos ligados à inovação. Por fim, a argumentação é no sentido não confundir compras públicas com processo de 'pickingwinner strategy', já que este define ou empresas, ou tecnologias para serem alavancadas. No caso das compras ${ }^{10}$, o importante é escolher áreas do mercado consideradas estratégicas para o desenvolvimento de processos inovativos.

No Plano de Ação (PACT\&I) 2007-2011, essa questão já é mencionada:

Este instrumento será mobilizado para promover o desenvolvimento tecnológico das empresas brasileiras, tanto por intermédio da compra direta de produtos e processos inovadores (como permitido pela Lei de Inovação), quanto pelo estabelecimento de contrapartidas de acesso a tecnologias na aquisição pelo governo, no exterior, de significativos lotes de produtos ou serviços. Alguns segmentos se afiguram preferenciais. Por exemplo, a indústria de produtos farmacêuticos surge como uma das primeiras áreas de aplicação desse instrumento, devido ao considerável porte das compras públicas no mercado nacional para esses produtos; e à importância deles para a saúde pública e, por último, ao fato desse setor ter sido incluído entre os prioritários da PITCE.

É importante fazer essa menção, dada a relevância que o tema tem apresentado nas discussões sobre as políticas de inovação, e a própria visão, do atual governo, de necessidade de integração da política de compras com as políticas de incentivos à inovação. Porém, não se pode negar que efetivos avanços ainda não podem ser observados na legislação brasileira, afinal nenhuma mudança legal recente foi observada.

De qualquer forma, a discussão deve ser acompanhada de transformações institucionais capazes de não permitirem usos incorretos, como o de favorecimento de grupos empresariais ou grupo de políticos ligados às compras governamentais. E por outro lado, é fundamental não perder de vista que se trata de uma forma de indução à inovação permitida pelas regras comerciais internacionais, tendo inclusive um manual adotado pela União Europeia ${ }^{11}$.

A prática do poder de compra do estado se aliada a um financiamento como a subvenção econômica pode se tornar uma ferramenta de grande efetividade na condução da melhoria do quadro da inovação no Brasil. No próprio documento do Plano 
de Ação do MCT há um item exclusivo sobre o uso do poder de compra do estado, parte do 'Programa de Inovação Tecnológica nas Empresas', apontando para a "necessidade do aperfeiçoamento do marco legal e da segurança jurídica na aplicação dos instrumentos e de esforço ainda maior para a consolidação e o aperfeiçoamento dessa política" (BRASIL, 2007:43). A argumentação presente no documento também relata exemplos, como o dos Estados Unidos, de uso do poder de compra incluindo apenas ressalva para empresas de residentes no país, mesmo que não sejam de base tecnológica, e pequenas empresas. Para o atual estágio das políticas de inovação no Brasil, as mudanças legais se configuram como fundamentais, sobretudo para viabilizar e dar maior escopo aos financiamentos públicos e, sem dúvida, o uso do poder de compra se configura como elemento central desse processo.

Finalizando as reflexões sobre essa questão das bases legais, ainda uma discussão se faz necessária: o direcionamento da subvenção a empresas brasileiras.

Os editais da subvenção econômica são aparados legalmente na Lei 10.973/2004, regulamentada pelo Decreto 5.563/2005, que prevê no parágrafo $3^{\circ}$ do seu Capítulo IV que: "Os recursos destinados à subvenção econômica serão aplicados no custeio de atividades de pesquisa, desenvolvimento tecnológico e inovação em empresas nacionais". Em primeiro lugar é importante ressaltar que não foram destinados recursos a empresas estrangeiras em nenhum de seus editais, porém duas empresas contratadas pela FINEP foram adquiridas por uma gigante multinacional que opera no país, são elas: Alellyx Applied Genomics e Canaviallis, empresas que, quando foram beneficiadas com o financiamento, estavam ligadas ao Grupo Votorantim, mais especificamente, controladas pela Votorantim Ventures Capital (VVenture).

Explicita-se aqui o nome das empresas, pois o caso se tornou público e as informações descritas a seguir foram compiladas do jornal Valor Econômico ${ }^{12}$. Em relação aos números, a primeira foi contemplada com o financiamento nos anos de 2006, 2007 e 2008 , tendo um valor total de contratos da ordem de $\mathrm{R} \$ 23.195 .014,38$ para projetos ligados ao desenvolvimento biotecnológico da cana-de-açúcar e eucalipto. Já a segunda, participou apenas nos anos de 2006 e 2008, porém com cifras ainda superiores, da ordem de $\mathrm{R} \$ 26.253 .604,56$, também em projetos ligados à cana-de-açúcar. As cifras correspondem, respectivamente, ao quinto e ao quarto maior financiamento particular da subvenção, sendo que as duas empresas em conjunto teriam angariado o segundo maior financiamento, inferior apenas a uma grande empresa do setor aeroespacial. É praticamente dispensável o comentário sobre a importância do desenvolvimento biotecnológico em relação às culturas por elas desenvolvidas, sobretudo a cana, tendo em vista o nosso volume de produção e nossa matriz energética, porém é fundamental comentar sobre a aquisição dessas duas empresas pela multinacional Monsanto no ano de 2008.

A trajetória histórica das duas empresas em questão nos remonta ao ano de 2000 com a criação do fundo Votorantim Venture focado em investimentos nas áreas de Tecnologia da Informação, Telecomunicações e Biotecnologia. A Alellyx foi a primeira empresa de risco do fundo. Criada através da associação de cinco cientistas do projeto Genoma no ano de 2002, a empresa tem linhas de pesquisa ligadas ao sequenciamento dos genomas de bactérias causadoras de doenças em plantas e análise dos genomas da cana-deaçúcar e eucalipto, duas culturas economicamente importantes para o país. 0 valor inicial do projeto gerido pelo fundo era de $\mathrm{R} \$ 30$ milhões, que seriam utilizados para construção de laboratórios e desenvolvimento das primeiras pesquisas. O laboratório 
foi inaugurado em novembro de 2002 com projetos para cana-de-açúcar, eucalipto e laranja, mas já com previsões de expansão para as culturas de soja e uva, sendo todos eles voltados a criação de produtos para a solução de problemas na produção dessas culturas. A questão da exploração de patentes era vista como central para a empresa, fato que se concretizou, a exemplo do sequenciamento do método de desenvolvimento de plantas transgênicas resistentes ao vírus da leprose, entre outros.

A outra empresa do grupo, a Cannvialis, foi criada em março de 2003 com investimentos previstos da ordem de $\mathrm{R} \$ 25$ milhões. Na sua concepção, a empresa estaria voltada às atividades ligadas à biotecnologia, neste caso particular, dedicadas ao melhoramento de variedades de cana-de-açúcar por meio da genética molecular. 0 modelo de associação com pesquisadores acadêmicos foi mantido, desta vez com a presença de cinco renomados cientistas oriundos da Universidade Federal de São Carlos. A proposta inicial contava com a criação de três estações experimentais, uma biofábrica, um laboratório de biologia molecular e outro de fitopatologia. Entre os objetivos da empresa eram destacados, a venda às usinas de cana-de-açúcar de pacotes tecnológicos completos, incluindo consultoria com vistas à otimização do uso das melhores variedades por região. Já no ano de 2006 a empresa era responsável pela genética de $10 \%$ das variedades de cana produzidas no Brasil, além de produzir, em Conchal (SP) um tipo de variedade que rende mais de $70 \%$ de sacarose por hectare. Sua expansão também foi considerável, de 2006 a 2007 a área atendida pela empresa passou de 120 mil hectares para 940 mil, segundo o Presidente à época Ricardo Madureira. A busca por novas variedade fez com que a empresa expandisse também seus polos de pesquisa, que hoje já totalizam sete espalhados pelo Brasil ${ }^{13}$.

Dada essa pequena apresentação do desenvolvimento dessas duas empresas, não faltam motivos que justifiquem a liberação de recursos não-reembolsável por parte da FINEP, fato que efetivamente se deu em cinco projetos. Afinal, eram empresas de biotecnologia, considerada área estratégica em todos os editais, e estavam lidando com o desenvolvimento de tecnologias fundamentais, vide a cana que além da sacarose é uma fonte de energia renovável em um período histórico marcado pela crescente busca por fontes alternativas de energia. Tanto a Alellyx, quanto a CanaVialis não só tiveram sucesso em seus projetos, como também desenvolveram várias parcerias quer com ICTs brasileiros, quer com a própria Monsanto. E aqui se inicia a contextualização da compra das duas empresas. Em maio de 2007 foi assinado um acordo entre a Alellyx, CanaVialis e Monsanto para o desenvolvimento de variedades de culturas convencionais e transgênicas. $O$ acordo previa compartilhamento de banco de germoplasmas, além do desenvolvimento de sementes transgênicas de milho, soja, algodão e canola tolerantes à seca. No caso da Alellyx o acordo significava sua entrada no mercado internacional, enquanto para a CanaVialis, que já havia exportado variedades para Angola, sua expansão. Segundo o jornal Valor Econômico (05/03/2007), nesta mesma época o presidente da CanaVialis havia anunciado, sem mencionar nome de empresas, que tinha sido procurado por investidores estrangeiros, o que não causa espanto, já que a empresa é, até hoje, a líder mundial em pesquisas com cana.

O fato é que no final de 2008 foi anunciada a aquisição por parte da Monsanto da Alellyx e CanaVialis. A Monsanto, que já liderava pesquisas com soja, milho e algodão, estendeu suas atribuições à cana também. Quanto a estratégia dessa gigante mundial, não há o que ponderar, ou melhor, não é interesse da presente análise. Porém, essas empresas foram contempladas com quase $\mathrm{R} \$ 50$ milhões apenas da FINEP, tendo ainda recebido empréstimos do BNDES no valor de aproximadamente $\mathrm{R} \$ 39$ milhões com juros 
conhecidamente mais módicos no Brasil, cerca de 4,5\% ao ano, situação deverás favorável se tratando de financiamentos públicos. A questão normativa volta a ter destaque. Ou seja, não há como negar que houve uma lacuna legal que permitiu a aquisição destas empresas por uma multinacional, o que por sua vez distorce os objetivos centrais deste modelo de financiamento à inovação pautado no desenvolvimento da inovação tecnológica em empresas brasileiras.

\section{Subvenção Econômica}

Feitas as apreciações institucionais e legais, a partir de agora se iniciam as análises das questões quantitativas e qualitativas ligados à Subvenção Econômica. Conforme explicitado na introdução, os dados utilizados fazem parte de uma compilação de estatísticas feita pelo IPEA, porém para ilustrarmos alguns pontos da evolução da política, utilizamos também as informações da publicação do resultado da SELEÇÃo PÚBLICA MCT/FINEP/FNDCT Subvenção Econômica à Inovação - 01/2009. Fato que não nos permite análises mais aprofundadas para o mesmo ano, mas exibe um panorama mais amplo.

Além de uma descrição dos contratos por ano, procurou-se avaliar outras questões importantes, como: sua distribuição espacial; sua distribuição por áreas estratégicas; sua distribuição em relação ao porte das empresas participantes; e o cruzamento entre as empresas contratadas pela subvenção com outras linhas de fomento à inovação. Por fim, procurou-se, a partir do porte das empresas e da localização nos estados brasileiros, estabelecer um perfil das empresas participantes do programa.

O panorama geral da Subvenção Econômica pode ser visto na tabela abaixo:

Tabela 2 - Valores e Número de Projetos nos Quatro Anos de Subvenção Econômica

\begin{tabular}{|l|c|c|c|c|c|}
\hline $\begin{array}{c}\text { Valores (RS } \\
\text { milhões)/Ano }\end{array}$ & $\mathbf{2 0 0 6}$ & $\mathbf{2 0 0 7}$ & $\mathbf{2 0 0 8}$ & $\mathbf{2 0 0 9}$ & Total \\
\hline Disponivel & 300 & 450 & 450 & 450 & 1650 \\
\hline Adicional & 0 & 0 & 64 & 17 & 81 \\
\hline Aprovado & 274 & 313,8 & 514 & 466 & 1567,8 \\
\hline Não executado & 26 & 136,2 & 0 & 0 & 162,2 \\
\hline Projetos (n $^{\circ}$ ) & & & & & \\
\hline Solicitados $_{\text {Aprovados }}$ & 1099 & 2567 & 2664 & 2558 & 8888 \\
\hline & 145 & 174 & 245 & 261 & 825 \\
\hline
\end{tabular}

Fonte: FINEP

Como se pode observar na Tabela 2, o padrão que deveríamos esperar para o programa, aumento do número de projetos solicitados e valores aprovados constantes, não foi verificado. No ano de 2006, o edital previu recursos para o financiamento da ordem de R\$ 300 milhões. Destes houve a não execução de R\$ 26 milhões. A partir de então, os recursos previstos subiram para $\mathrm{R} \$ 450$ milhões, sendo que apenas no ano de 2007, o programa não executou o total disponibilizado, sobrando, para o mesmo ano, uma quantia considerável: mais de R\$ 136 milhões. Já nos anos de 2008 e 2009, se verifica que a os valores aprovados subiram consideravelmente, contando com recursos superiores aos previstos nos editais. Segundo consta no 'Relatório de Gestão FINEP 2008', o valor 
adicional de R\$ 64 milhões, no mesmo ano, foi uma decisão da própria instituição, com base no acórdão no 2876/2008 do Tribunal de contas da União (TCU).

Apenas um fato chama atenção, que é a queda tanto do valor total contratado em 2009, quanto dos projetos solicitados, saindo um pouco da lógica que seria aguardada, afinal com o passar dos anos, a tendência seria que um maior número de empresas participasse do processo seletivo. Uma das hipóteses que pode ser levantada é que a concorrência dada pelo crescente número de participantes nos anos anteriores, o aumento da contrapartida exigida às grandes empresas e a burocracia demandada pelo processo todo de seleção servem de elementos desmotivadores às empresas. Por outro lado, apenas o fato de a FINEP ter alterado a chamada pública em apenas uma fase, como mencionado na seção anterior, também pode contribuir com a explicação, o que, de qualquer maneira, necessita de comprovação empírica para ser afirmado.

Segue-se que o valor global da Subvenção de mais de R\$ 1,5 bilhão, assim como o número total de projetos que participaram do processo seletivo, cerca de 8888, são consideráveis e dão indício de uma política que, em termos de alcance, tem possibilidades de bons resultados.

Quanto a continuidade do programa de subvenção, segundo o 'Plano Plurianual (PPA) 2008-2011' do MCT, há previsão de orçamento do FNDCT para a Subvenção Econômica até o ano de 2011, ainda que até meados de 2010 o edital de subvenção não tenha sido lançado. A previsão de recursos é próxima dos valores anuais, cerca de $\mathrm{R} \$ 477$ milhões por ano. Esse montante representaria cerca de $21 \%$ do total de gastos previstos pelo FNDCT para os anos de 2010 e 2011.

A questão da distribuição territorial dos recursos segue a concentração das atividades de ciência e tecnologia no país, ou seja, forte participação das regiões sul e sudeste, com destaque para o Estado de São Paulo ${ }^{14}$. Em todos os editais havia menção a obrigatoriedade de destinação de $30 \%$ dos recursos para as regiões Centro-Oeste, Nordeste e Norte, mas no mesmo item havia também uma ressalva: caso não haja projetos classificados, os recursos poderão ser aplicados em outros projetos recomendados para aprovação. 0 Gráfico 1 deixa claro não só a concentração nas destinações dos recursos, como também explicita que em nenhum dos quatro anos do financiamento as regiões que deveriam ter parcelas garantidas sequer chegaram perto de obter os $30 \%$ de direito. Apenas no ano de 2007 é que tivemos um aumento da participação da região Nordeste, mas que não só voltou a cair nos anos seguintes, como, se somadas às regiões $\mathrm{CO}$ e $\mathrm{N}$, a participação conjunta dessas regiões não atingiu os $30 \%$. É importante atentar para a relação entre a porcentagem de empresas contratadas e o valor do contrato por região. Para as regiões $\mathrm{CO}, \mathrm{N}, \mathrm{NE}$ e $\mathrm{S}$ a porcentagem de empresas contratadas é sempre maior do que os valores, o que revela uma participação ainda menor dessas regiões nos valores contratados em proporção à participação das empresas. Apenas na região SE é que a porcentagem das empresas é menor que o valor contratado, o que indica que os projetos aprovados dessa região são mais caros do que os projetos das outras. Isso se verifica quando analisamos os dez maiores contratos em todos os anos, incluindo 2009, dos 40 maiores projetos, 24 são de empresas localizadas em São Paulo, somando aproximadamente $\mathrm{R} \$ 238$ milhões, sendo que o segundo estado mais significativo é o Rio de Janeiro, com apenas três empresas e cerca de R\$37 milhões. 


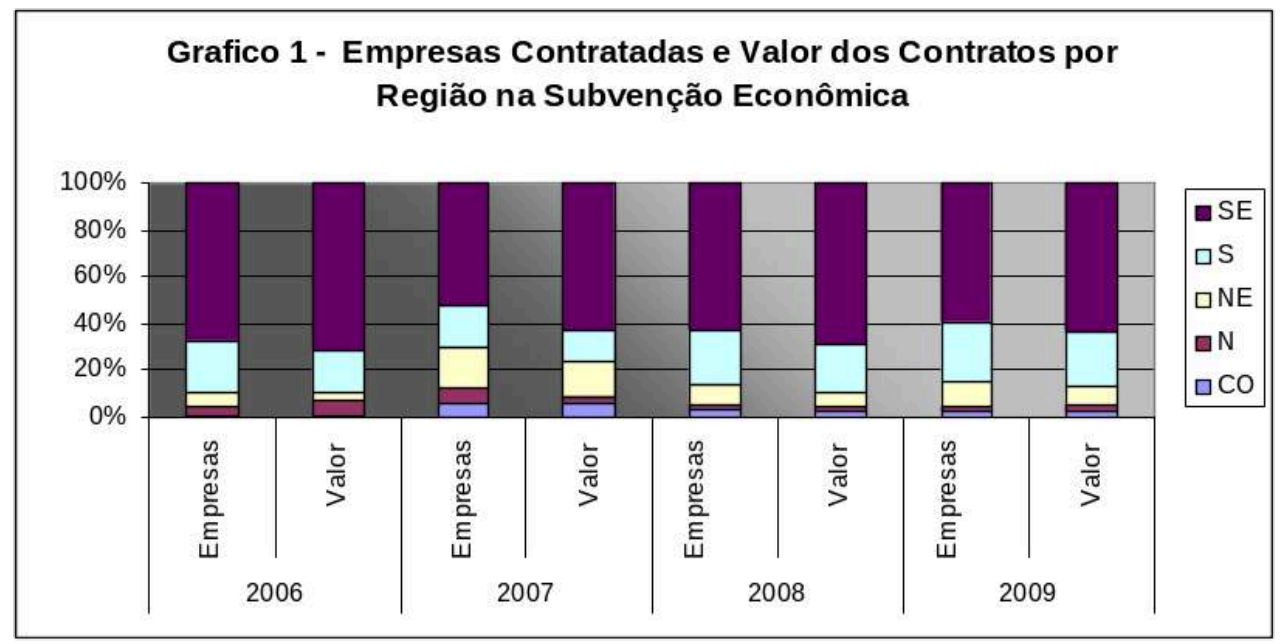

Um fundo não-reembolsável obviamente é de interesse de qualquer empresa, mesmo que ele apresente alto grau de burocracia ou qualquer outra negatividade. Afinal "os mecanismos destinados a financiar investimentos em inovação tecnológica são diferentes daqueles voltados ao financiamento convencional, principalmente por conta dos riscos envolvidos e do tempo de retorno, que tendem a ser maiores" (CORDER E SALLES-FILHO, 2006:36), o que torna esse tipo de financiamento escasso. Dito isso, diferente de um financiamento para aquisição de máquinas ou melhorias de infraestrutura, a inovação trata de uma linha que apresenta um conjunto de riscos e, portanto, não seria correto um financiamento para esse fim sem estabelecimento de critérios e mais importante, áreas de interesse, setores que tivessem real importância de serem contemplados e de poderem contribuir com o desenvolvimento do país ${ }^{15}$. E é neste sentido que todos os editais foram definidos em consonância com a política industrial e tecnológica do Brasil. A maneira através da qual isso se tornou possível foi o estabelecimento de áreas estratégicas, todas previstas como prioritárias na PITCE, PDP ou PACT\&I. Em relação as áreas, observam-se alterações ao longo dos anos, porém, hoje, já se encontram de forma mais delimitada e clara tanto para as empresas, quanto para os próprios responsáveis pela seleção dos beneficiados.

As áreas prioritárias do primeiro edital foram definidas com base na portaria ministerial MCT/MDIC $n^{\circ}$ 597. À época houve total consonância com a PITCE, afinal os setores estratégicos da política eram: software, bens de capital, fármacos e medicamentos. Se observada a portaria interministerial supracitada, as prioridades para a subvenção, segundo os parágrafos $2^{\circ}$ e $3^{\circ}$ foram duas: áreas estratégicas, com semicondutores, software, bens de capital e fármacos e medicamentos; e áreas portadoras de futuro, com biotecnologia, nanotecnologia e biomassa/energia alternativa. Na seleção dos projetos de 2006, segundo os dados da FINEP disponíveis no banco de dados do IPEA, os critérios tiveram como base áreas que iam desde as claramente estabelecidas, como, aeroespacial, bens de capital, biotecnologia, energias alternativas, fármacos e medicamentos, nanotecnologia e TV Digital, passando por áreas que contemplavam diferentes setores, como 'Aplicações Mobilizadoras Estratégicas', que incluíam Tecnologias da Informação e Comunicação (TIC), defesa, saúde, educação e agronegócio, e 'Geral', que além das sete áreas claramente estabelecidas, também acabou por contemplar adesivos, engenharia e arquitetura, indústria cerâmica, madeira e móveis e têxtil. 
O que se observou foi que apesar de termos tido alguns setores definidos, nesse ano houve uma flexibilidade maior nas propostas e no desembolso de contrato para áreas não diretamente ligadas à política industrial, a exemplo de 'cerâmica', fato que, como veremos a seguir, não viria a se repetir nos outros anos. Exatamente por esse motivo que para os anos seguintes algumas análises estatísticas com base na definição das áreas estratégicas foram realizadas, o que não foi possível para o ano de 2006, sobretudo por essa diversidade de temas.

A partir do ano de 2007 houve uma padronização maior em relação à definição de áreas e temas prioritários. Basicamente, todas as áreas que seriam vigentes para os anos de 2008 e 2009 estavam contempladas em 2007. Suas definições foram feitas com base nas Portarias Ministeriais 597 de 2006 e 554 de 2007. Porém o texto do edital é exatamente igual ao da portaria de 2007. Uma análise um pouco mais aprofundada dos editais nos leva a afirmar que a política, a partir desse ano, já foi definida de maneira mais clara quanto seus objetivos, tendo apenas pequenas mudanças no conteúdo das áreas estratégicas, como evidenciado no acréscimo do setor de energia eólica ${ }^{16}$ na área de 'Energia' no ano de 2009, já que até este ano o edital priorizava apenas o desenvolvimento de tecnologias voltadas aos bicombustíveis, em geral e as tecnologias ligadas a cana-de-açúcar, em particular.

Além de reservar uma área estratégica ligada ao desenvolvimento de tecnologias sociais, chama atenção o fato de no ano de 2008, nas definições mais especificas da área da saúde, termos tido menção a integração da política de inovação com o SUS, já que o segundo item do edital deixa explicita o "desenvolvimento de moléculas com alto potencial no campo sanitário e/ou impacto nos gastos do Sistema Único de Saúde (SUS)". o que torna claro o direcionamento ainda maior das políticas de inovação para a uma integração com as políticas sociais, elemento de extrema relevância na definição de prioridades em C\&T.

Finalizando essa breve descrição, nos anos de 2008 e 2009 a única mudança foi a passagem da área de 'Programas Estratégicos' para 'Defesa Nacional e Segurança Pública', o que não altera de maneira significativa seu conteúdo. Afinal, as prioridades foram dadas à projetos ligados ao desenvolvimento de sistemas de navegação, materiais específicos (alta densidade e emissores de pósitrons) do setor, assim como tecnologias aeroespaciais.

De maneira geral, podemos afirmar que a definição das áreas estratégicas seguiu um padrão de consonância com as políticas industriais e de inovação do país, sempre procurando estabelecer, sobretudo com o passar dos anos, aspectos cada vez mais específicos para as áreas estratégicas.

Em relação à distribuição dos recursos pelas áreas, desde o primeiro edital havia previsão de distribuição equitativa por todas as áreas, exceto 'Desenvolvimento Social' que teve, em todos os anos, uma porcentagem inferior dos recursos. O que se nota na Gráfico $2^{17}$ é que houve concentração em algumas áreas, a não ser pelo ano de 2008 que se observa uma melhor distribuição dos recursos pelas áreas, ainda que não se possa falar em uma boa distribuição. Da mesma forma, com base nos dados se torna complicado auferir alguma conclusão, sobretudo, pela irregularidade da distribuição nesses primeiros anos. A área de 'Biotecnologia' é emblemática nesse sentido, de uma participação de 4,7\% em 2007, sobe abruptamente para $20,8 \%$ em 2008 e volta a 5,9\% em 2009, ou seja, parece ainda não haver critérios claramente definidos para a seleção dos projetos por áreas, mesmo estando previsto nos editais, o que indica uma variação do 
próprio conteúdo das propostas. A ressalva fica por conta das áreas de 'Saúde', que se manteve em uma crescente ao longo dos anos, e a dos 'Programas Estratégicos' que apesar da queda em 2008, manteve sempre o maior quinhão dos recursos aprovados.

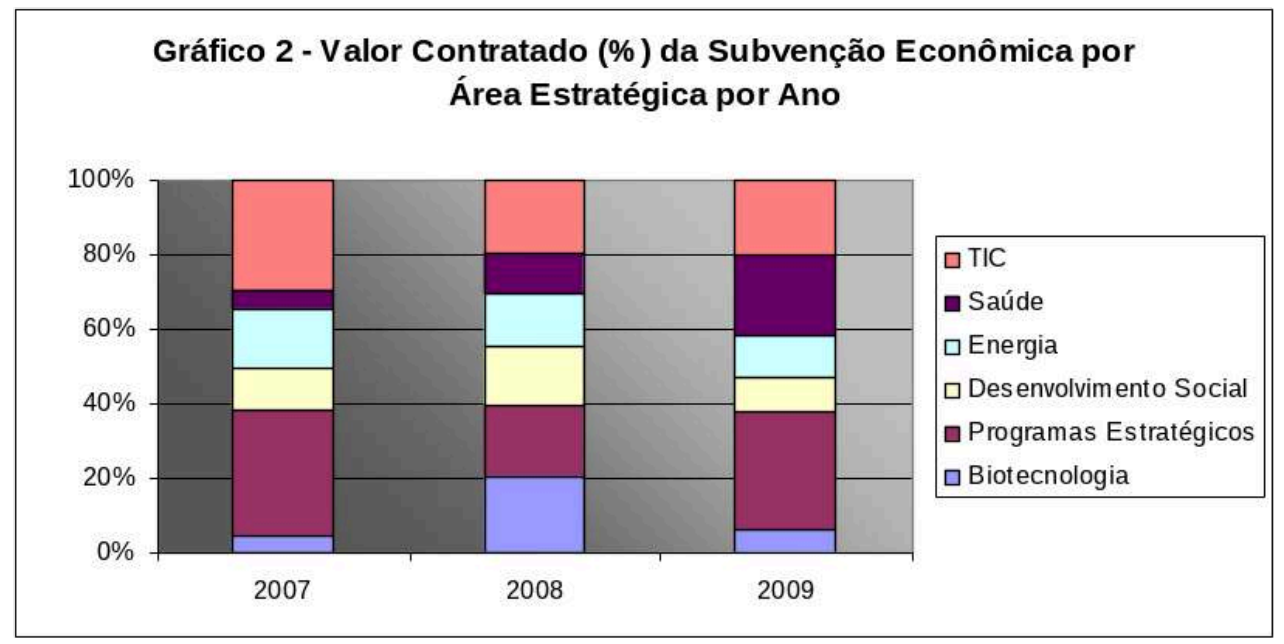

A última análise antes de entrarmos nas questões relativas sobreposição de financiamentos para inovação é em relação ao porte das empresas contratadas. 0 critério adotado pela FINEP para realizar a distinção das empresas por porte foi 'critério mercosul': Microempresa e Pequeno Porte, faturamento até R\$ 2,4 milhão; Pequena Empresa, faturamento entre $\mathrm{R} \$ 2,4$ milhão e $\mathrm{R} \$ 10,5$ milhões; Média Empresa, entre $\mathrm{R} \$ 10,5$ milhões e $\mathrm{R} \$ 60$ milhões; e as de Grande Empresa são aquelas com faturamento maior que $\mathrm{R} \$ 60$ milhões.

Apesar da quebra de padrão no ano de 2007, o que se verifica é uma clara tendência de diminuição da participação de empresas de grande porte e aumento de microempresas/ pequeno porte e pequena empresa (ver Gráfico 3). Isso é visível também quando analisamos os maiores projetos financiados pelo programa. Afinal, projetos com valores superiores a R $\$ 10$ milhões deixam de existir em 2009. A queda de participação das grandes empresas é drástica, sendo que em 2009 obtiveram apenas 6,4\% do valor contratado.

A explicação para a mudança no padrão da política, ou seja, do fortalecimento de micro e pequenas empresas, está no fato da contrapartida financeira ${ }^{18}$ exigida pela financiadora ter se mantido para microempresa e pequeno porte em $5 \%$, e para pequena empresa em $20 \%$, enquanto para média e grande empresa subiu de $40 \%$ para $100 \%$ e de $60 \%$ para $200 \%$, respectivamente. Este dado demonstra claramente que a FINEP nada mais fez do que acompanhar a PDP, lançada em 2008, que deixava explicita a necessidade de fomentar a inovação em empresas de menor porte e para tal, dificultou em muito o acesso às grandes empresas ao financiamento, já que a cada $R \$$ 100 requeridos, a empresa deveria dar uma contrapartida de $\mathrm{R} \$ 200$. Se por um lado o foco dos incentivos em empresas de menor porte tem suas justificativas, como ser um instrumento de incentivo à inovação em empresas sem capacidade financeira para tal, o incentivo às grandes empresas também pode exercer um papel fundamental em tecnologias de ponta e setores estratégicos, como o de defesa, que requerem grandes aportes financeiros. 
O Gráfico 4 indica a diminuição considerável do desembolso para Grandes empresas em 2008, relatada acima, pouco mais de $10 \%$, assim como a sua considerável participação no total da contrapartida financeira, mais de $40 \%$.

Image

10007A440000556300002B3E24D05C41BF2C1E5F.emf

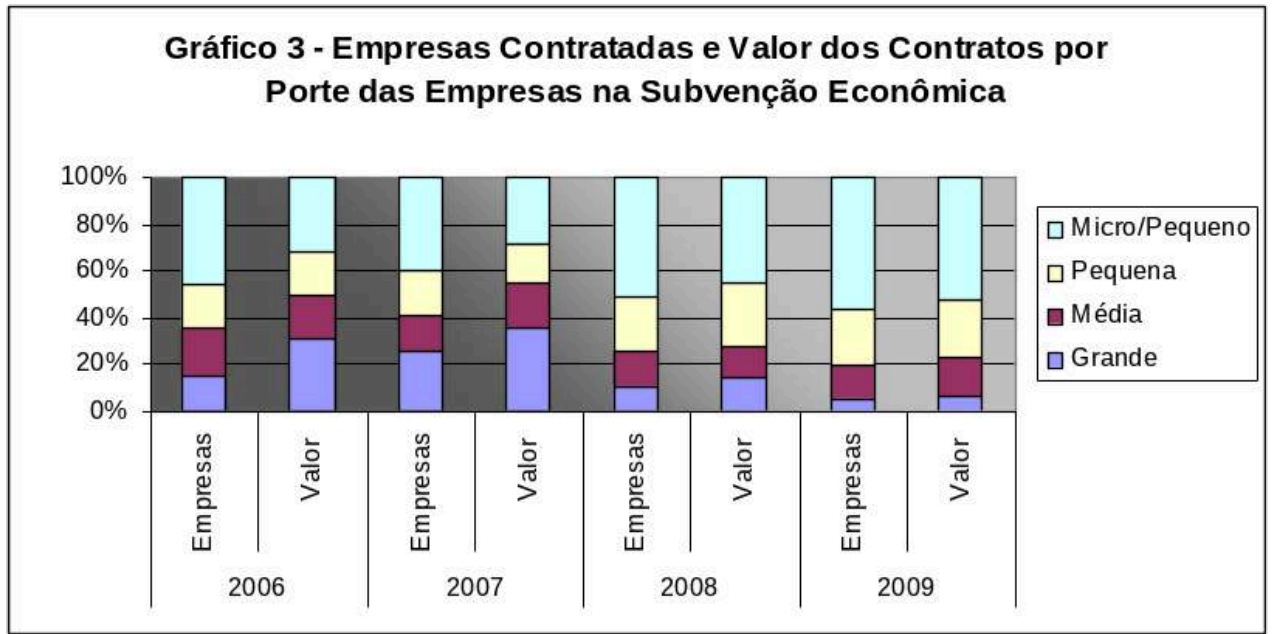

Image

100071880000556300002B3E55EE5C100E58783D.emf
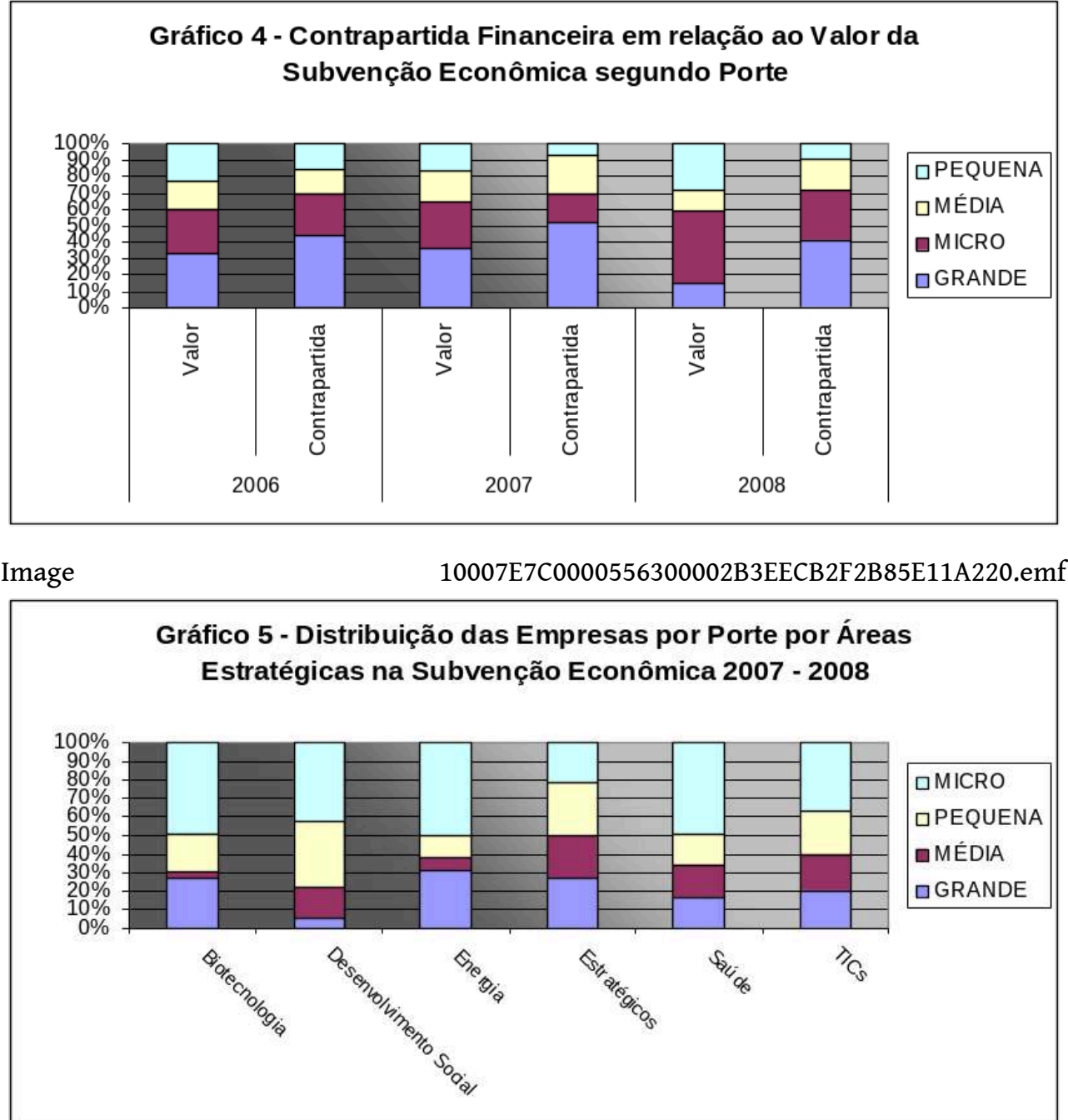
Por fim, o Gráfico 5 revela a distribuição das empresas por porte em função das áreas estratégicas. As que ganham destaque em relação às grandes e médias empresas são energia e estratégicos, sendo esta última a única que basicamente $50 \%$ dos desembolsos são para grandes e médias empresas. Isso se justifica pelos elevados investimentos necessários para inovação em áreas como a aeroespacial e de defesa. Já os setores que tiveram perfil de empresas participantes parecidos foram: biotecnologia, saúde e TICs. Teoricamente deveríamos esperar também a participação de empresas de maior porte na saúde, porém o setor só veio a ser diretamente contemplado em $2008^{19}$, ano em que já prevalecia a contrapartida maior. Participação realmente pouco significativa de grandes empresas foi verificada no setor de desenvolvimento social, que apresentou a maior participação de micro e pequenas empresas.

A partir deste momento, passaremos a verificar o grau de inter-relação da subvenção com outras políticas de incentivo à inovação. Arbix (2007) ressaltou a necessidade de "definir estratégias que permitam coordenar ações de desenvolvimento social com objetivos de promover a inovação e o conhecimento preservando a visão de longo prazo". Quanto às recomendações, Arbix (idem) afirmou ser fundamental desenvolver no interior da PITCE um programa de fomento às inovações empresariais em tecnologias de alto impacto econômico e social, assim como, repensar e readequar os instrumentos de fomento, de financiamento e de incentivos fiscais para torná-los mais eficientes no estímulo à inovação empresarial, em especial, compatibilizando a legislação de incentivos fiscais e integrando sua gestão (entre setores e nos três níveis federativos) construindo um sistema nacional de crédito e financiamento para todas as modalidades de C\&T\&I, articulado com o BNDES, a FINEP e Fundos Setoriais. O que, no nosso caso, poderia ser evidenciado pela utilização e conhecimento de incentivos pelas empresas contratada da subvenção nas diversas instituições fomentadoras de inovação, assim como seu conhecimento de incentivos fiscais para inovação.

Uma das questões inicialmente pensadas foi como seria a articulação das empresas contratadas pela FINEP com outras linhas de fomento à inovação do governo federal. Nesse sentido, a preocupação foi entender se de alguma forma a existência de outros mecanismos de fomento eram conhecidos ou utilizados pelas empresas contratadas pela FINEP. Ou seja, se a empresas tinham alguma institucionalidade em relação a busca de outras formas de financiamento à inovação, sobretudo, porque o projeto exigido no modelo de subvenção é extremamente complexo, o que teoricamente colocaria a empresa em condições de solicitar outros fomentos e indicaria que as linhas de financiamento do governo estão conhecidas e articuladas. Como houve cruzamento de bancos de dados distintos, não foi possível uma padronização de todas as informações ${ }^{20}$. É importante deixar claro que todos os cruzamentos foram realizados com base em todas as empresas contratadas nos três primeiros anos de subvenção e com as bases históricas disponíveis para os outros incentivos. Ou seja, a relevância procurada foi se em algum momento a empresa contratada pela FINEP já utilizou outra forma de incentivo, mesmo que em anos passados. Um exemplo pode ser dado pela empresa ' $\mathrm{X}$ '21 que participou de dois projetos vinculados aos Fundos Setoriais em 2001 e 2004, respectivamente e foi contemplada com três projetos na subvenção econômica, nos anos de 2006 e 2007. A seguir, dar-se-á início às análises.

o primeiro cruzamento foi feito entre as empresas contratadas na subvenção e as empresas que participaram de projetos dos Fundos Setoriais (FS). 
Tabela 3 - Empresas participantes da Subvenção Econômica da FINEP e dos Fundos Setoriais até 2008

\begin{tabular}{|c|c|c|c|}
\hline Fundo & Empresas & Valor FINEP (R\$) & $\begin{array}{l}\text { Valor Fundo Setorial } \\
\text { (R\$) }\end{array}$ \\
\hline CT-AERONAUTICO & 7 & $122.049 .632,35$ & $90.900 .062,29$ \\
\hline CT-AGRONEGÓCIO & 0 & . & . \\
\hline CT-AMAZÔNIA & 0 & . & . \\
\hline CT-AQUAVIÁRIO & 5 & $10.914 .131,52$ & $3.608 .374,88$ \\
\hline CT-BIOTECNOLOGIA & 2 & $4.747 .251,11$ & $1.506 .600,00$ \\
\hline CT-ENERGIA & 6 & $9.877 .824,84$ & $2.239 .795,83$ \\
\hline CT-ESPACIAL & 1 & $3.954 .594,00$ & $249.400,00$ \\
\hline CT-HIDRO & 1 & $500.000,12$ & $201.600,00$ \\
\hline CT-INFO & 22 & $39.072 .655,43$ & $10.030 .581,61$ \\
\hline CT-INFRAESTRUTURA & 0 & . & . \\
\hline CT-MINERAL & 0 & . & . \\
\hline CT-PETRÓLEO & 8 & $25.277 .016,44$ & $4.539 .574,56$ \\
\hline CT-SAÚDE & 0 & . & . \\
\hline CT-TELECOMUNICAÇÃO & 0 & . & . \\
\hline CT-TRANSPORTE & 0 & . & . \\
\hline CT-TRANSVERSAL & 64 & $213.014 .860,88$ & $80.643 .692,20$ \\
\hline CTFTEL & 11 & 37.417.146,39 & $45.953 .190,83$ \\
\hline FNDCT & 7 & $25.898 .708,38$ & $5.806 .857,66$ \\
\hline OUTFON & 7 & $12.912 .327,67$ & $5.705 .289,82$ \\
\hline VERDE E AMARELO & 15 & $136.581 .571,19$ & $24.313 .849,35$ \\
\hline
\end{tabular}

Obs: os cruzamentos foram realizados com as empresas que acessaram, até o ano de 2008, simultaneamente a subvenção econômica e os fundos setoriais, mesmo que o acesso tenha ocorrido em anos diferentes.

\section{Fonte: FINEP}

A análise da Tabela 3 indica que nos FS houve predomínio de participação de empresas contratadas na subvenção no CT-TRANSVERSAL e CT-INFO. O primeiro parece ser mais 
óbvio, afinal trabalha em articulação com os outros fundos e foi concebido apenas no ano de 2004. Mas o que podemos perceber é que de todos os cruzamentos, esse - FS - foi um dos que apresentou maior número de empresas contempladas nos dois financiamentos. $O$ fato de serem geridos pela mesma instituição é um indicativo de um conhecimento maior das possibilidades de financiamento da mesma, até porque as informações ficam disponíveis em um mesmo sítio na pagina da FINEP na web. Vale a pena observar também que os desembolsos da subvenção foram sempre consideravelmente superiores que os do FS, a não ser pelo caso do CT-AERONAUTICO, que os valores foram muito próximos.

$O$ outro grande cruzamento que verificamos diz respeito às oito modalidades do BNDES, ver Tabela 4. Nele encontramos um número considerável de empresas da subvenção que buscaram algum tipo de financiamento do BNDES. Chama a atenção, sobretudo, a modalidade Máquinas e Equipamento, que infelizmente não distingue, no banco de dados, investimento para P\&D. A modalidade de Mercado de Capital nos chamou a atenção, já que se esperava um número maior de empresas ligadas à subvenção e que teriam sido capitalizadas pelo programa BNDES Parceiro (BNDESPAR), porém quando analisados os dados, encontramos uma pequena adesão de empresas da subvenção nessa modalidade. Em outras operações como Financiamento a Empresa e BNDES Automático, mais difundidas, seria de se esperar uma participação maior das empresas da subvenção, fato representado na tabela abaixo.

Tabela 4 - Empresas participantes da Subvenção Econômica da FINEP e das Modalidades BNDES

\begin{tabular}{|l|l|l|l|}
\hline Modalidade & Empresas & Valor Finep (R\$) & Valor BNDES (R\$) \\
\hline Financiamento a Empresa & 33 & $255.310 .202,62$ & $4.710 .320,90$ \\
\hline Maquinas e Equipamentos & 62 & $457.282 .062,00$ & $9.125 .657,70$ \\
\hline BNDES - Exim & 17 & $384.010 .136,41$ & $45.920 .238,70$ \\
\hline Mercado de Capitais & 8 & $83.437 .544,37$ & $516.910,30$ \\
\hline Aval & 0 &. &. \\
\hline Não Reembolsável & 0 &. &. \\
\hline Financiamento ao Fabricante & 2 & $9.913 .264,00$ & $191.409,90$ \\
\hline BNDES Automático & 40 & $262.713 .710,99$ & $26.279 .608,40$ \\
\hline
\end{tabular}

Fonte: FINEP, BNDES

A existência de um programa para inovação no CNPq levou ao interesse pelo cruzamento de dados desse com a subvenção. $O$ fato de ser uma agência tradicionalmente voltada ao fomento de atividades em universidades e centros de pesquisa chamou atenção. o programa com o qual foi realizada a sobreposição foi o de Formação de Recursos Humanos em Áreas Estratégica (RHAE), criado em 1987, que tinha suas atribuições geridas pelo MCT. Porém, após algumas mudanças, em 1997 ele ficou sob responsabilidade do CNPq e a partir de 2002 passou a ser chamada de RHAE- 
Inovação. Com base no banco de dados da referida bolsa para os anos de 2004 a 2008, procuramos as empresas da subvenção que acessaram esse fomento. 0 número de empresas foi relativamente pequeno, não chegando nem a $10 \%$ do total das empresas contratadas na subvenção, ver Tabela 5. A finalidade de servir, sobretudo a micro e pequenas e médias empresas foi constatada, sendo a maioria dos casos de microempresas. Porém, é representativo o fato de o valor dos projetos aprovados para subvenção para as microempresas ser aproximadamente $\mathrm{R} \$ 51$ milhões, muito acima do valor dos desembolsos para as microempresas da RHAE, que é cerca de $\mathrm{R} \$ 8,8$ milhões.

Tabela 5 - Empresas participantes da Subvenção Econômica da FINEP e da bolsa RHAE

\begin{tabular}{|l|l|l|l|l|}
\hline \multicolumn{2}{|l|}{ FINEP } & \multicolumn{2}{l|}{ CNPq RHAE } \\
\hline Porte Empresa & Valor (R\$) & № de empresas & Valor (R\$) & № de empresas \\
\hline Microempresa & $51.246 .291,00$ & 26 & $8.864 .505,00$ & 26 \\
\hline Pequena & $12.503 .635,00$ & 6 & $2.333 .166,00$ & 6 \\
\hline Total & $63.749 .925,00$ & 32 & $11.197 .671,00$ & 32 \\
\hline
\end{tabular}

Fonte: FINPE, CNPq/RHAE.

Por fim, realizamos o cruzamento das empresas contratadas na subvenção e as empresas participantes da Lei do Bem (ver Tabela 6). 0 total de empresas aprovadas na subvenção e que utilizam a Lei do Bem ainda é pequeno, se levado em conta o fato dessas empresas terem um, mesmo que pequeno, setor de P\&D. Porém, quando analisamos a sobreposição dos outros instrumentos com a Lei do Bem, os resultados da subvenção não são tão díspares.

Tabela 6 - Empresas participantes da Subvenção Econômica da FINEP e da 'Lei do Bem'

\begin{tabular}{|l|l|l|}
\hline Porte & № de Empresas & Valor FINEP (R\$) \\
\hline Grande & 27 & $174.178 .181,00$ \\
\hline Média & 10 & $73.991 .906,00$ \\
\hline Pequena & 3 & $12.656 .189,00$ \\
\hline Micro & 1 & $3.954 .594,00$ \\
\hline Total & 41 & $264.780 .870,00$ \\
\hline
\end{tabular}

Fonte: FINEP, MCT

Segundo De Negri et all. (2010:19), que também realizou uma sobreposição de instrumentos para inovação, o maior grau de sobreposição entre os instrumentos foi observado entre a Lei do Bem (incentivos fiscais) e os projetos reembolsáveis (crédito). As conclusões do estudo apontam que é "razoável supor que exista uma 
complementaridade importante entre esses dois mecanismos: os incentivos fiscais reduzem o custo associados ao processo de inovação, mas não garantem que as empresas tenham, no momento do investimento, os recursos necessários para investir no projeto de P\&D, o que é feito por meio de mecanismos de crédito". No caso da subvenção, apesar de não-reembolsável, a sobreposição entre as empresas contratadas e as beneficiarias da Lei do Bem, revelou uma participação ainda tímida, em torno de 9\% das empresas. Já nas linhas do BNDES, créditos para aquisição de máquinas e equipamentos foi o que mais apresentou sobreposição, cerca de $14 \%$. O que por sua vez, condiz com as estatísticas realizadas por De Negri et all. (idem).

As últimas análises deste item são referentes ao perfil das empresas sob três perspectivas: por Unidades da Federação (UF); pelo porte das empresas; e por último, por comparação entre empresas contratadas da subvenção com as contratadas pelos FS e as presentes na RAIS. Os dados foram compilados com base na RAIS e na SECEX. Em função de ainda não haver resultados disponíveis nos bancos de dados citados para o ano de 2008, utilizamos os dados de 2007 para as empresas contratadas na subvenção em 2008.

Em relação ao perfil das empresas contratadas na subvenção por UF, ver Tabela 7, os resultados demonstram uma variedade de situações, ou seja, conclusões sobre o perfil das empresas com base no desenvolvimento dos estados são impraticáveis para as empresas contratadas na subvenção. Um primeiro exemplo pode ser o Rio de Janeiro que detém os valores mais baixos em relação ao número de patentes e às exportações e, ao mesmo tempo, apresenta a terceira média mais elevada de pós-graduandos empregados nas empresas.

Tabela 7 - Perfil das Empresas Contratadas na Subvenção Econômica da FINEP por UF 2006, 2007 e 2008

\begin{tabular}{|c|c|c|c|c|c|c|c|c|}
\hline UF & $\begin{array}{l}\text { Número } \\
\text { de } \\
\text { Empresas }\end{array}$ & Contratos_Medio & PO_TGrau_Medio & PosGrad_Medio & Renda_Media & msal_Media & \begin{tabular}{|l|} 
Número \\
Médio de \\
Patentes
\end{tabular} & $\begin{array}{l}\text { Valor Médio } \\
\text { Exp. }\end{array}$ \\
\hline AM & 13 & 331,4 & 67,9 & 0,0 & 1.412 & 7.832 .796 & 0,0 & 14.478 .271 \\
\hline CE & 14 & 26,7 & 15,0 & 0,1 & 1.044 & 400.285 & 0,0 & 0 \\
\hline PB & 3 & 15,1 & 2.8 & 0,3 & 759 & 122.126 & 0,0 & 0 \\
\hline PE & 17 & 92,0 & 31,8 & 0,1 & 1.301 & 1.594 .589 & 0,0 & 1.934 .910 \\
\hline BA & 9 & 339,3 & 157,9 & 6,6 & 2.608 & 21.129 .163 & 0.6 & 109.295 .274 \\
\hline MG & 41 & 288,8 & 73,1 & 0,9 & 1.440 & 12.069 .223 & 0,0 & 93.325 \\
\hline RJ & 39 & 67,3 & 37.7 & 1,9 & 2.291 & 2.678 .073 & 0,0 & 94.311 \\
\hline SP & 165 & 300,8 & 118,1 & 1,0 & 2.584 & 14.015 .121 & 0,2 & 45.026 .250 \\
\hline PR & 27 & 172,9 & 42,4 & 0,5 & 1.400 & 2.800 .211 & 0,1 & 8.697 .992 \\
\hline SC & 34 & 321,1 & 78,0 & 0,7 & 1.660 & 7.189 .811 & 0,1 & 5.279 .904 \\
\hline RS & 37 & 191,8 & 39,9 & 0,8 & 1.684 & 3.843 .897 & 0,1 & 3.659 .341 \\
\hline GO & 7 & 25,4 & 7,7 & 0,0 & 982 & 298.095 & 0,0 & 15.023 \\
\hline DF & 7 & 438,7 & 272,1 & 0,1 & 1.819 & 16.611 .009 & 0,0 & 31.470 \\
\hline
\end{tabular}

Fonte: RAIS, SECEX 
Tabela 8 - Perfil das Empresas Contratadas na Subvenção Econômica da FINEP por Porte - 2006, 2007 e 2008

\begin{tabular}{|l|l|l|l|l|l|l|l|l|l|}
\hline \multicolumn{1}{|c|}{ Porte } & $\begin{array}{c}\text { Número } \\
\text { de } \\
\text { Empresas }\end{array}$ & $\begin{array}{c}\mathbf{N}^{\circ} \text { Médio } \\
\text { de } \\
\text { Contratos } \\
\text { no Ano }\end{array}$ & $\begin{array}{c}\mathbf{N}^{\circ} \text { Médio de } \\
\text { Funcionarios } \\
\text { com Terceiro } \\
\text { Grau }\end{array}$ & $\begin{array}{c}\mathbf{N}^{\circ} \\
\text { Médio } \\
\text { de } \\
\text { Mestres } \\
\text { e } \\
\text { Doutores }\end{array}$ & $\begin{array}{c}\mathbf{N}^{\circ} \\
\text { Médio } \\
\text { de } \\
\text { Patentes }\end{array}$ & $\begin{array}{c}\text { Valor Exportado } \\
\text { Médio }\end{array}$ & $\begin{array}{c}\text { Valor Finep } \\
\text { Médio }\end{array}$ & $\begin{array}{c}\text { Contrapartida } \\
\text { Financeira } \\
\text { Média }\end{array}$ & Faturamento Média \\
\hline MICRO & 178 & 12,39 & 4,47 & 0,35 & 0,02 & $33.441,93$ & $1.717 .710,95$ & $1.101 .448,93$ & $1.752 .995,15$ \\
\hline PEQUENA & 100 & 36,87 & 12,51 & 0,06 & 0,03 & $109.268,21$ & $2.000 .207,91$ & $706.733,09$ & $13.173 .296,63$ \\
\hline MÉDIA & 75 & 172,08 & 48,21 & 0,92 & 0,08 & $3.158 .672,97$ & $2.349 .790,39$ & $2.439 .155,29$ & $49.395 .339,75$ \\
\hline GRANDE & 69 & $1.177,32$ & 414,91 & 3,76 & 0,46 & $129.699 .933,52$ & $3.532 .891,86$ & $5.213 .611,68$ & $2.545 .895 .786,74$ \\
\hline
\end{tabular}

Fonte: RAIS, SECEX

Tabela 9 - Comparação do Perfil das Empresas - RAIS, Fundos Setoriais e Subvenção Econômica FINEP - 2006, 2007, 2008

\begin{tabular}{|c|c|c|c|c|c|c|c|c|}
\hline Grupo & $\begin{array}{l}\mathbf{N}^{\circ} \\
\text { Empresas }\end{array}$ & tam_med & estudo_med & idade_med & $\begin{array}{l}\mathbf{N}^{\circ} \\
\text { Exportadoras }\end{array}$ & $\begin{array}{l}\text { \% } \\
\text { Exportadoras }\end{array}$ & $\begin{array}{l}\mathbf{N}^{\circ} \\
\text { Patenteadoras }\end{array}$ & $\begin{array}{l}\text { \% } \\
\text { Patenteadoras }\end{array}$ \\
\hline RAIS & 2.236 .106 & 17,0 & 9,2 & 9.7 & 24.641 & $1,10 \%$ & 12.250 & $0.55 \%$ \\
\hline FS & 1.664 & $1.457,7$ & 11,7 & 28,7 & 287 & $17,25 \%$ & 302 & $18,15 \%$ \\
\hline SUB & 433 & 412,4 & 11,6 & 15,3 & 132 & $30,48 \%$ & 93 & $21,48 \%$ \\
\hline
\end{tabular}

Fonte: RAIS, SECEX

De maneira geral, o perfil das empresas contratadas na subvenção não nos permite uma análise mais efetiva do financiamento por estado. Afinal, houve, para os três primeiros anos uma irregularidade em relação às empresas participantes tanto no que diz respeito aos desembolsos por estados, quanto por porte, vide variação considerável ao longo dos anos, sobretudo se observada a diminuição do contrato de grandes empresas no ano de 2008. O caso da Bahia é revelador. O estado, que detém médias de patentes e de exportação elevadas, merece atenção. 0 valor elevado, sobretudo, das exportações, diz respeito à participação de grandes empresas nos dois primeiros anos da subvenção $\mathrm{e}$ ao pequeno número de empresas contratadas, fato que diminui a participação de empresas de menor porte e, portanto, não 'dilui' os resultados, como no caso das empresas participantes de São Paulo.

De qualquer forma, as exportações indicam uma ainda baixa participação de empresas exportadoras na subvenção econômica. Na maior parte dos estados os valores são extremamente baixos, sendo que apenas Bahia, São Paulo e Amazonas têm médias de exportação superiores a R $\$ 10$ milhões.

Já a relação entre exportação e patentes, retirando o caso do Amazonas, apresentou forte conexão, sendo os estados que mais exportam os que têm média de patentes maiores. Porém, isso não diminui a importância de se observar médias extremamente baixas de patentes nas empresas em todos os estados analisados.

Os dados relativos ao grau de instrução do pessoal ocupado também apresentaram variação considerável, dificultando a análise. O Distrito Federal apesar de configurar como a maior média de pessoal ocupado com terceiro grau, tem um percentual médio de pessoal ocupado com pós-graduação insignificante, cerca de $0,1 \%$.

Se compararmos os graus de instrução com a renda média e a massa salarial, chegaremos à mesma variabilidade de situações. $O$ que nos permite ressaltar que as empresas contratadas na subvenção não oferecem análises regionalizadas relevantes. A hipótese é que, dada a amostragem ainda pequena de empresas e à participação de grandes empresas nos primeiros anos, a consequente grande variação do porte das 
empresas contratadas aufere resultados desproporcionais se os dados forem regionalizados.

Já as análises do perfil das empresas por porte seguiram uma tendência mais esperada. A observação do perfil das empresas por porte foi feita com base no banco de dados da FINEP, o que remete ao 'critério Mercosul' (explicitado anteriormente). A opção por não utilizar o critério do IBGE para indústria se deu pelo motivo de nem todas as empresas contratadas no financiamento serem industriais.

A análise da Tabela 8 traz resultados mais óbvios, ou seja, as maiores médias em todas as variáveis são relativas às empresas de grande e médio porte. As grandes empresas, sobretudo para as médias de 'valor exportado' e 'faturamento', são consideravelmente superiores, o que indica a participação de empresas realmente importantes nos seus nichos de mercado. Mesmo assim, é relevante observar que o número médio de patetes dessas empresas é relativamente pequeno, considerando os dados antes mencionados, o que indica uma política ainda tímida em relação às patentes no Brasil. Quanto ao valor FINEP para os três anos, ainda se verifica um maior aporte de recursos para as grandes empresas, resultado dos grandes contratos nos dois primeiros anos de subvenção, situação que tende a se inverter dado o aumento da contrapartida exigida

Porém, chamam à atenção as variáveis de 'número de mestres e doutores' e 'contrapartida financeira' comparadas entre as micro e pequenas empresas. Nos dois casos as microempresas apresentam médias mais elevadas do que as pequenas, mesmo com faturamento médio mais de sete vezes superior da última. A justificativa

se dá pelo fato de apenas duas microempresas, com números bem superiores nessas duas variáveis, aumentarem as médias, caso contrário a tendência por porte seria mantida.

A comparação entre as empresas da subvenção com as empresas participantes da RAIS e dos FS revelou dados interessantes, ver Tabela 9. As empresas participantes da subvenção econômica apresentam porcentagem de empresas exportadoras e com patentes superior às outras duas amostragens, apesar do tamanho médio e do grau de instrução médio serem inferiores às empresas dos FS. Já na comparação de todas as variáveis, as empresas da subvenção apresentaram capacidade de inovação muito superiores às da RAIS, sobretudo se observadas as diferenças entre as variáveis de patentes e de exportação.

Os números relativos à subvenção econômica revelaram alguns aspectos interessantes, sobretudo uma variação ainda muito grande tanto nos parâmetros de seleção, quanto das próprias empresas participante, que, por sua vez, proporcionam resultados um pouco fora dos padrões esperados. De qualquer forma, as análises demonstraram um financiamento que vem se consolidando e se tornando cada vez mais estruturado do ponto de vista dos seus objetivos.

\section{Considerações Finais}

O ineditismo da subvenção econômica no Brasil, além de sua brevidade, merece atenção. Ao longo de quatro anos esse mecanismo de indução à inovação teve abrangência considerável tanto no que diz respeito ao número de empresas beneficiadas quanto ao volume de recursos despendidos. Ainda que seja muito cedo para conclusões assertivas, a política aqui discutida ressalta mudanças na condução do 
sistema nacional de inovação brasileiro. Sua dimensão em termos das transformações institucionais e legais, promovidas no MCT, na FINEP e na legislação brasileira, são exemplos claros disso, sobretudo se observado o fato do programa constar no PPA do governo federal para os próximos anos. Porém, não se pode negar a existência de gargalos e, neste sentido, alguns apontamentos se fazem necessários.

O desenvolvimento de estratégias legais aparece como elemento fundamental para a continuidade do programa. As questões relativas às compras governamentais e um maior comprometimento das empresas contratadas se mostraram centrais para a melhoria do programa, tendo em vista, sobretudo, que ele chegue cada vez mais próximo dos seus objetivos.

Dois principais requisitos da política em questão aparecem desde o primeiro edital: a necessidade de fomentar a inovação em micro e pequenas empresas e a urgência de ter um alcance territorial para além da região mais desenvolvida do país, o Sudeste. Em relação ao primeiro, efetivamente foram observadas mudanças, tendo as empresas de menor porte aumentado sua participação ao longo dos anos. Já a tentativa de desconcentrar territorialmente o financiamento, ainda que configure como um dos objetivos centrais do programa, não foi verificada, revelando uma maior capacidade de uso do território pelas empresas localizadas nos centros mais dinâmicos do país, com forte ênfase na participação do estado de São Paulo nos desembolsos. Por outro lado, a análise do perfil das empresas não indica que as empresas deste estado são as mais inovadoras, apesar de serem as que mais participaram do programa, o que, por sua vez também pode ser justificado pela presença de empresas de todos os portes.

Em relação às análises do perfil das empresas, o fato da subvenção ser recente, o número de contratos ainda não ser relativamente grande e ter havido uma mudança nos objetivos do programa - com aumento da participação de micro e pequenas empresas, nos leva a consideração de que análises como esta devem continuar sendo feitas com o intuito de acompanhamento constante dos resultados efetivos da subvenção, afinal, houve uma irregularidade considerável no processo de contratação nos primeiros anos do programa, fato que tende a diminuir nos próximos anos.

A despeito de ser um financiamento criado e efetivado no Governo Lula, não podemos de forma alguma atribuir seus sucessos e problemas a um ou outro governo. Nas apreciações sobre as questões normativas e institucionais procurou-se deixar claro que a subvenção é resultado de um processo que evidencia uma política de Estado e não uma política de governo, decidida por tal ou qual partido, ainda que tenhamos tido um incremento das políticas de incentivo à inovação. É neste sentido que a sua condução e desenvolvimento futuro devem permanecer indiferente de políticas partidárias.

\section{BIBLIOGRAFIA}

ALMEIDA, Mansueto, Desafios da Real Política Industrial Brasileira do Século XXI. Brasília: IPEA, Texto para Discussão, n 1452, 2009. 
ARBIX, Glauco. Inovar ou inovar: a indústria brasileira entre o passado e o futuro. $1^{\mathrm{a} E}$ Edição, São Paulo: Editora Papagaio, 2007.

ARBIX, Glauco. Projeto Metodologia para Conceber e Executar Plano de Mobilização Brasileira pela Inovação Tecnológica - MOBIT. ABDI/CEBRAP Produto 2: Resenha bibliográfica, São Paulo: $2007 \mathrm{a}$

ARBIX, Glauco e Mendonça, Maurício. Inovação e competitividade: uma agenda para o futuro. In: CASTRO, A. A.; LICHA, A.; PINTO JR., H. Q. e SABÓIA, J. Brasil em Desenvolvimento, v.1: economia, tecnologia e competitividade. Rio de Janeiro: Civilização Brasileira, 2005, págs: 233-170.

AVELLAR, Ana Paula. Avaliação do impacto do PDTI sobre o gasto em atividades de inovação e em P\&D das empresas industriais. In: De Negri, João Alberto \& Kubota, Luis Claudio (editores). Políticas de Incentivo à Inovação Tecnológica. Brasília: IPEA:2008, p. 323- 358.

BARBOSA, Denis Borges. Incentivos fiscais no contexto da Lei Federal de Inovação. dezembro de 2004 (no prelo).

BASTOS, Valéria Delgado. Fundos Setoriais de Ciência e Tecnologia. In: PINTO, M. P. A. e BIASOTO Jr., G. Política fiscal e Desenvolvimento no Brasil. Campinas-SP: Editora da Unicamp, 2006.

BRASIL. Plano de Ação 2007-2010. Ciência, Tecnologia e Inovação para o Desenvolvimento Nacional. Brasília: MCT, 2007a.

BRASIL. Relatório Anual de Utilização dos Incentivos Fiscais. Ano Base 2008. Lei Nº 11.196/05. Brasília: MCT, 2008.

BRASIL. Plano Plurianual (PPA) 2008-2011. Brasília, DF: Ministério de Ciência e Tecnologia, 2009.

CAPANEMA, Luciana Xavier de Lemos, PALMEIRA FILHO, Pedro Lins e PIERONI, João Paulo. Apoio do BNDES a Complexo Industrial da Saúde: experiência do Profarma e seus desdobramentos. In: BNDES Setorial $n^{\circ} 27$, Rio de Janeiro, n. 27, p. 3-20, mar. 2008.

CGEE. Descentralização do Fomento à Ciência, Tecnologia e Inovação no Brasil. Brasília, DF: Centro de Gestão e Estudos Estratégicos, 2010.

CORDER, Solange e SALLES-FILHO, Sergio. Aspectos Conceituais do Financiamento à Inovação. Rio de Janeiro (RJ): Revista Brasileira de Inovação, Volume 5 Número 1 janeiro/ Junho 2006.

COUTINHO, L. G. Macroeconomic Regimes and Business Strategies: an Alternative Industrial Policy for Brazil in the Wake of the 21st Century. In: CASSIOLATO, José Eduardo; LASTRES, Helena M. M.; MACIEL, Maria Lucia (orgs.). Systems of Innovation and Development: Evidence from Brazil. Sussex: Sussex University, 2003, v. 01, p. 311-329.

DE NEGRI, Fernanda et al. Metodologia de Avaliação dos Resultados de Conjuntos de Projetos Apoiados dor Fundos de Ciência, Tecnologia e Inovação (C,T\&I). Relatório n² Perfil das Empresas Integradas ao Sistema Federal de C,T\&I no Brasil e aos Fundos Setoriais: uma Análise Exploratória. s/1, 2010.

DE NEGRI, João Alberto; SALERNO, Mario Sergio; e CASTRO, Antonio Barros de. Inovações, padrões tecnológicos e desempenho das firmas industriais brasileiras. In: DE NEGRI, João Alberto e SALERNO, Mario Sergio (orgs.). Inovações, Padrões Tecnológicos e desempenho das firmas industriais brasileiras. Brasília: IPEA, 2005, p.5-48.

EDLER, Jakob and GEORGHIOU, Luke. Public procurement and innovation: Resurrecting the demand side. Manchester, UK: Research Policy, 36, pag. 949-963, 2007.

FAPESP. Fundação de Amparo à Pesquisa do Estado de São Paulo. Indicadores de FAPESP de C\&T\&I em São Paulo, 2010. mimeo. 
FINEP. Financiadora de Estudos e Projetos. Agência Brasileira de Inovação. Formas de Atuação. 2004.

FINEP. Financiadora de Estudos e Projetos. Relatório de Gestão 2009 S/l. s/d.

FINEP. Financiadora de Estudos e Projetos. Relatório de Gestão 2008. S/l. s/d.

FINEP. Financiadora de Estudos e Projetos. Relatório de Avaliação do Programa de Subvenção Econômica. s/l. Janeiro de 2010.

GUIMARÃES, Eduardo Augusto. Políticas de Inovação: Financiamentos e Incentivos. In: DE NEGRI, João Alberto e KUHBOTA, Luis Claudio (editores). Políticas de Incentivo à Inovação Tecnológica. Brasília: IPEA:2008, p.149 - 228.

IEDI. Instituto de Estudos para o Desenvolvimento Industrial. Desafios da Inovação. Incentivos para Inovação: o que falta ao Brasil. s/1. 2010.

MCT, CGEE, $3^{a}$ Conferência Nacional de Ciência, Tecnologia e Inovação: síntese das conclusões e recomendações. Brasília, DF: Ministério da Ciência e Tecnologia, Centro de Gestão e Estudos Estatégicos, 2006.

PIRRÓ E LONGO, Waldimir e DERENUSSON, Maria Sylvia. FNDCT, 40 Anos. Rio de Janeiro (RJ): Revista Brasileira de Inovação, 8 (2), p.515-533, julho/dezembro 2009

PRESIDÊNCIA DA REPÚBLICA. Casa Civil. Diretrizes de política industrial, tecnológica e de comércio exterior. Brasília: Casa Civil, 2003. 23p.

SALERNO, Mario Sergio; e KUBOTA, Luis Cláudio. Estado e Inovação. In: DE NEGRI, João alberto e KUHBOTA, Luis Claudio (editores). Políticas de Incentivo à Inovação Tecnológica. Brasília: IPEA: 2008, p.13- 64 .

VILLASCHI FILHO, A. Anos 90: uma década perdida para o sistema nacional de inovação brasileiro? In: São Paulo em Perspectiva, v. 19, 2005, p. 3-20.

Jornal Valor Econômico:

- Votorantim eleva aposta na cana, em 26/03/2003.

- Investidores financiam mapeamento genético, em 23/04/2003.

- Capital de risco investe menos em 6 meses, mas privilegia novas firmas, em 14/11/2003.

- Falta de lei dificulta pesquisa, em 04/06/2004.

- Alellyx mapeia genoma do vírus da leprose dos citros, em 08/04/2005.

- Brasil lidera pesquisa com cana transgênica, em 13/04/2005.

- Biotecnologia atrai capital privado, em 08/08/2005.

- Pouca verba para pesquisas com cana, em 13/04/2006.

- Votorantim avalia vender patente de cana transgênica ao exterior, em 28/08/2006.

- Investimento público em pesquisa agrícola perde fôlego e espaço, em 06/11/2006.

- Capital sai em busca de projetos mais maduros Intel, em 22/02/2007.

- "Febre do etanol" valoriza as pesquisas da CanaVialis, em 05/03/2007.

- Biotecnologia aproxima Votorantim e Monsanto, em 30/05/2007.

- Pesquisas genéticas, em 06/07/2007.

- Com juros 4,5\% ao ano, BNDES financia projetos de inovação de empresas do grupo Votorantim, em 05/07/2007.

- Monsanto paga US\$290 milhões por duas empresas do Grupo Votorantim, em 04/11/2008.

- Apostas financeiras sacodem a Votorantim, em 27/11/2008.

- Fusões e aquisições caem 7\% no ano, aponta PricewaterhouseCoopers, em 29/12/2008.

- MDM agora é 100\% da Monsanto, em 04/03/2009.

- Fundo da Burrill investirá no Brasil R\$100 milhões, em 29/01/2010.

- Contexto, em 27/04/2010.

- Adquirida pelo Apax, Tivit mira exterior, em 11/05/2010. 


\section{NOTAS}

1. Este artigo um dos resultados da pesquisa "Fundos Setoriais e Sistema Nacional de Inovação: Uma Análise Exploratória", capitaneado pelo IPEA e financiado pelo Ministério de Ciência e Tecnologia. Gostaria de agradecer em especial à Fernanda De Negri e ao João De Negri pela oportunidade.

2. Os dados compilados são oriundos: da Pesquisa Industrial Anual (PIA) e da Pesquisa Industrial sobre Inovação Tecnológica (Pintec), ambas do Instituto Brasileiro de Geografia e Estatística (IBGE); da Relação Anual de Informações Sociais (Rais), do Ministério do Trabalho e Emprego (MTE); da Secretaria de Comércio Exterior (Secex), do Ministério de Desenvolvimento Indústria e Comércio Exterior (MDIC); do Censo do Capital Estrangeiro (CCE) e do registro de Capitais Brasileiros no Exterior ( $\mathrm{CBE}$ ), do Banco Central (Bacen); do Instituto Nacional de Propriedade Industrial (Inpi), da Base de Dados de Compras Governamentais do Ministério do Planejamento, Orçamento e Gestão (MPOG); do Programa de Capacitação de Recursos Humanos para Atividades Estratégicas (RHAE) do Conselho Nacional de Desenvolvimento Cientifico e Tecnológico (CNPq).

3. $O$ déficit na balança comercial do setor de medicamentos cresceu, só no período de $2000-2008$, 130\% (CAPANEMA, PALMEIRA FILHO e PIERONI, 2008).

4. De Negri, Salerno e Castro (2005:11) afirmam que: "a remuneração média mensal do pessoal ocupado é R\$ 1.254,64 nas firmas que inovam e diferenciam produtos; R\$ 749,02 nas firmas especializadas em produtos padronizados; e $\mathrm{R} \$ 431,15$ nas firmas que não diferenciam produtos e têm produtividade menor".

5. Em 2006 apenas $11 \%$ das empresas brasileiras utilizavam algum tipo de financiamento público, (MCT, CGEE, 2006).

6. Segundo Guimarães (2008:177) “a Lei $\mathrm{n}^{\circ}$ 10.637, aprovada em 2002, ampliava os incentivos então existentes. Paralelamente, a Lei $\mathrm{n}^{\mathrm{o}} 10.332$, do mesmo ano, autorizava a concessão de subvenção econômica a empresas engajadas" do PDTI e PDTA. Vale ressaltar que essas leis não permitiam a subvenção na maneira como é realizada hoje.

7. Informações disponíveis no sítio: http://www.mct.gov.br/index.php/content/view/8477.html

8. Almeida (2009) realizou um estudo sobre a eficácia da política industrial e tecnológica do Governo Lula. Entre suas conclusões, há especial atenção para o fato de a política não ter surtido o efeito esperado, dado o aumento do déficit na balança comercial, sobretudo, ligado aos setores de alta e média tecnologia. É inegável esse aumento no déficit, porém os resultados de uma política industrial e tecnológica não são esperados nos anos seguintes aos seus lançamentos, ou seja, os resultados esperados se dão no médio e longo prazo, ficando ainda muito incipiente uma conclusão negativa sobre a efetividade da política.

9. As críticas a esse modelo advêm do fato da escolha ser baseada em empresas já competitivas fazendo com que "PMEs (pequenas e médias empresas) estejam sub-representadas no grupo de empresas apoiadas" (IEDI, 2010).

10. Segundo Elder e Georghiou (2007:953): “We can distinguish general procurement practice versus strategic procurement, direct public procurement (where the goods or services are exclusively for public use) versus catalytic procurement and, finally, commercial versus precommercial procurement".

11. EUROPEAN COMMISSION. "Guide on dealing with innovative solutions in public procurement - 10 elements of good practice". Luxembourg: Office for Official Publications of the European Communities, $2007-26$ pp.

12. Todas as informações sobre as duas empresas foram extraídas do jornal Valor Econômico, as referências encontram-se na bibliografia.

13. Pólos Regionais de Tecnologia: São Paulo - Centro; São Paulo - Oeste; Minas Gerais, Paraná; Tocantins; Maranhão; e Nordeste. 
14. A partir de duas fontes de dados se pode verificar a extrema discrepância do estado de São Paulo em contraponto com outras Unidades da Federação. Segundo CGEE (2010) os recursos aplicados em C\&T em relação à receita total no estado de São Paulo em 2008 era de 3,67\% e o gato total de C\&T em porcentagem do PIB estadual, 0,39\%. Para se ter uma idéia, o segundo estado com maior participação nas duas variáveis é o Paraná com, respectivamente, 2,67\% e 0,26\%. Já para a FAPESP (2010), que contabilizou também a participação das instituições federais e das empresas, o despendido total em P\&D no estado foi de aproximadamente 1,52\% do PIB Estadual em 2008, ficando a frente não só do Brasil, como da Espanha e Índia, entre outros.

15. Incluindo o fato de a Subvenção Econômica ser possível, segundo as normas da OMC, para atividades de CT\&I.

16. O total de projetos aprovados para a área de 'Energia' foi de 26, destes, 16 são para desenvolvimento de tecnologias ligadas a produção de energia eólica.

17. Para fins de análise as áreas foram definidas conforme a nomenclatura do ano de 2008 . Algumas ressalvas são importantes: no ano de 2007, a área 'Saúde' estava dispersa em outras áreas, sendo assim, procuramos na variável 'classificação' apenas os projetos vinculados à palavra 'saúde'; no ano de 2009 a área 'Programas Estratégicos' foi modificada para 'Defesa Nacional e Segurança Pública', porém os objetivos tiveram pequenas alterações pontuais.

18. A contrapartida financeira exigida é a porcentagem em relação ao valor aprovado pela subvenção.

19. No ano de 2007 não havia uma área específica apenas para a saúde. A área que contemplava a saúde era a mesma de biodiversidade e biotecnologia, ver nota 12 .

20. O melhor exemplo é o cruzamento entre as bolsas do CNPq e a Subvenção Econômica da FINEP. O banco de dados da primeira instituição não contém o CNPJ das empresas, o que dificultou o cruzamento, já que em cada banco a razão social pode conter diferenças de grafia.

21. Preferimos deixar em sigilo o nome da empresa.

\section{RESUMOS}

Após um período de abandono das políticas industriais e de inovação mais incisivas, o estado brasileiro retomou o modelo lançando em 2003 a Política Industrial, Tecnológica e de Comércio Exterior (PITCE). Dentre suas linhas, a subvenção econômica ganhou destaque a partir do uso de recursos da Financiadora de Estudos e Projetos (FINEP) e tendo uma mudança central que foi a possibilidade de financiamento para empresas privadas. Suas diretrizes estiveram ligadas à PITCE e este artigo é resultado de uma análise feita exatamente sobre suas implicações políticas e territoriais no período inicial, entre 2006 e 2009, desse financiamento que se mostrava muito pertinente à época. Dois elementos chamaram bastante a atenção no estudo. Apesar de mecanismos de descentralização dos desembolsos, o que se observou foi uma concentração na região Sudeste. Por outro lado, o tamanho das empresas beneficiadas acabou sendo de grande porte, não favorecendo empresas que geralmente têm maiores dificuldades de capitação de recursos para a inovação.

After a period of abandoning more incisive industrial and innovation policies, the Brazilian state resumed the model, launching the Industrial, Technological and Foreign Trade Policy (PITCE) in 2003. Among its lines, the economic subsidy gained prominence from the use of resources from the Financier of Studies and Projects (FINEP) and having a central change that was the possibility 
of financing for private companies. Its guidelines were linked to PITCE and this article is the result of an analysis made exactly about its political and territorial implications in the initial period, between 2006 and 2009, of this funding that proved to be very relevant at the time. Two elements stood out in the study. Despite disbursement decentralization mechanisms, what was observed was a concentration in the Southeast region. On the other hand, the size of the benefited companies ended up being large, not favoring companies that generally have greater difficulties in raising funds for innovation.

Après un période d'abandon des politiques industrielles et d'innovation plus incisives, l'État brésilien a repris le modèle d'intervention en lançant la Politique Industrielle, Technologique et de Commerce Extérieur (PITCE en portugais). Dans ce cadre, les subventions ont vu le jour à partir des ressources de l'agence financière d'études et de projets (FINEP), en particulier ceux qui ont voués aux entreprises privées. Ainsi, cet article analyse les effets politiques et territoriaux de ce grand changement entre 2006 et 2009. Deux éléments doivent être séparés : (i) malgré les mécanismes de décentralisation des décaissements, on constate le phenomène de la concentration dans la Région Sud-Est ; (ii) les entreprises beneficiées ont été celles de grand taille, et non les petites entreprises déjà caracterisées par la difficulté de captation des ressources liés à l'innovation.

Después de un período de abandono de políticas industriales y de innovación más incisivas, el Estado brasileño retomó el modelo de intervención con el lanzamiento de la Política Industrial, Tecnológica y de Comercio Exterior (PITCE). En este contexto, han surgido subvenciones con cargo a los recursos de la Agencia Financiera de Estudios y Proyectos (FINEP), en particular las dedicadas a empresas privadas. Así, este artículo analiza los efectos políticos y territoriales de este gran cambio entre 2006 y 2009. Se deben separar dos elementos: (i) a pesar de los mecanismos de descentralización de los desembolsos, se observa el fenómeno de concentración en la Región Sudeste; (ii) las empresas beneficiadas fueron las de gran porte, y no las pequeñas empresas ya caracterizadas por la dificultad de captar recursos ligados a la innovación.

\section{ÍNDICE}

Keywords: territory; politics; economic subsidy; innovation; FINEP

Palabras claves: territorio; políticas; subvenciones económicas; innovación; FINEP

Palavras-chave: território; política; subvenção econômica; inovação; FINEP

Mots-clés: territoire; politiques; subventions économiques; innovation ; FINEP

\section{AUTOR}

\section{PABLO IBANEZ}

Mestre e Doutor em Geografia Humana pela USP. Professor Adjunto da Universidade Federal Rural do Rio de Janeiro. Email: ibanez.pablo@gmail.com 